\title{
Experimental and numerical study of the thermal and hydrodynamic characteristics of laminar natural convective flow inside a rectangular cavity with water, ethylene glycol- water and air
}

\author{
M. Mahdavi, M. Sharifpur", H. Ghodsinezhad, J.P. Meyer \\ *Corresponding author \\ "Tel: +27 124202448 "Email: mohsen.sharifpur@up.ac.za \\ 1,2, "Department of Mechanical and Aeronautical Engineering, University of Pretoria, \\ Private Bag X20, Hatfield, 0028, Pretoria, South Africa
}

\begin{abstract}
Laminar natural convection in a rectangular cavity with three different heat transfer fluids: water, ethylene glycol (EG)-water and air were studied experimentally and numerically. The enclosure has a uniform aspect ratio (AR). The EG-water mixture is made up of $60 \% \mathrm{EG}$ and $40 \%$ water. The main experiments aimed to reach proper thermal boundary conditions for the two differentially heated vertical walls of the cavity. Hence, two heating and cooling heat exchangers with water as the heat transfer fluid were attached to the cavity walls. All other walls were properly insulated. Early experiments revealed that it is hard for the heated and cooled walls to reach a uniform temperature when the cavity is filled with water or EG-water, while a uniform distribution of temperature was achieved when it is simply filled with air. Commercial computational fluid dynamics (CFD) software, ANSYS-FLUENT 15, simulated the entire setup to include two special heat exchangers and the cavity between them to investigate all the transport phenomena. The simulation results were in good agreement with measured data. The distortion of air flow is much higher than with the other two fluids. Water flow inside the cavity is flatter and a big circulation area was captured in the middle of the EG-water fluid flow. The local Nusselt number's three-dimensional distribution was presented on the walls. When compared to other fluids, the impact of the adiabatic walls in the air flow cavity on the Nusselt number was found to be considerable. Eventually, the roles of energy equation terms were studied. Convective terms were noticeable when compared to thermal diffusion.
\end{abstract}

Keywords: Natural convection, cavity flow, airflow, EG-water, CFD, Nusselt number

\section{Introduction}

Rectangular enclosures are widely employed in many industries. Examples include tank storage, energy transfer devices, reactor systems, solar collectors and engine cooling systems. One of the most common thermal boundary conditions is constant or uniform temperature on two opposite walls. A large number of studies have focused numerically and experimentally on natural air convective flow inside enclosures. This is discussed below.

Benchmark and comparison studies of air-filled cavities were carried out by Davis $[1,2]$ in a laminar regime for Rayleigh numbers up to $10^{6}$. The Nusselt number at the mid-plane of the cavity was found to be almost similar to average Nusselt numbers in these studies. Schmidt 
Giel, Phillipst and Wang [3] conducted experimental and two-dimensional investigations for a water-filled cavity in a laminar regime for Rayleigh numbers up to $10^{8}$. They showed that the hydrodynamic boundary layer is extremely thin in the walls and the flow is thermally stratified in most parts of the core region. A comparison between theory and experimentation by Heindel, Incropera and Ramadhyani [4] for a Prandtl number higher than air (water with $\operatorname{Pr} \sim 5$ and Fluorinert ${ }^{\mathrm{TM}}$ Electronic Liquid FC-77 with $\operatorname{Pr} 25$ ) in a cavity with a twodimensional analysis provided a $20 \%$ underestimation for the Nusselt number. However, the aspect ratios (the vertical length of the diabatic walls in relation to the horizontal distance between them) were chosen to be above 4. A Nusselt correlation for a cavity filled with air and aspect ratios above 40 was presented in experimental work by Shewen, Hollands and Raithby [5]. Fusegi and Hyun [6] and Hiroyuki, Akira and Masaru [7] reviewed air- and water-filled cavities, mainly with the two-dimensional assumption. Lartigue, Lorente and Bourret [8] captured the existence of secondary flow inside an air-filled cavity with a laminar Rayleigh number less than $10^{5}$. They found good agreement between two-dimensional numerical model and experimental results. Ampofo and Karayiannis [9] conducted experiments on an air-filled cavity in a turbulent regime with a Rayleigh number above $10^{9}$ and differentially heated vertical walls. They explained that the maximum Nusselt number occurs at the bottom and top of the hot and cold walls, due to the very thin thermal boundary layer. They stated that air-filled cavities with an aspect ratio above 1.8 can be treated as twodimensional models. Bairi, Laraqi and Garcia de Maria [10] performed an experimental study on an air-filled cavity with a turbulent flow and a Rayleigh number up to $10^{8}$. The Nusselt number correlation achieved from their work was compared to previous correlations for aspect ratios of 0.75 and 1.5. They also reported that two-dimensional numerical results are in good agreement with the measurement.

In recent years, many studies of water-filled cavities focused on the application of nanofluids (mostly numerical approaches) [11-14]. A few experimental works are presented for water inside a cavity $[15,16]$, especially transient analyses of the thermal boundary layer for a Rayleigh number higher than $10^{10}$ [17]. Imberger [18] measured the temperature and velocity inside a differentially heated water-filled cavity with vertical walls and aspect ratios less than 0.02. He illustrated the presence of a parallel flow and the lack of a flat distribution of temperature from the hot to the cold walls. Moreover, a sinusoidal profile of velocity was captured between two horizontal insulated walls.

Turan, Poole and Chakraborty [19] numerically investigated the laminar convective flow inside air- and water-filled cavities with various aspect ratios. They proposed new correlations for the Nusselt numbers in terms of aspect ratio, as well as Prandtl and Rayleigh numbers. Wu and Ching [20] performed experiments on an air-filled cavity in a laminar regime with Rayleigh numbers below $10^{8}$. Through the use of adjustable electrical heaters mounted on the hot walls, and cold heat exchangers attached to the cold walls with water as the working fluid, they stated that a uniform wall temperature was reached in both the hot and the cold walls due to the low heat flux. They presented the general form of correlation for the Nusselt number as $\mathrm{C} . \mathrm{Ra}^{\mathrm{n}}$, with constant numbers depending on the aspect ratio. They also reported the separation from the top wall and secondary circulation flow in all three aspect ratios. Kumar and Eswaran [21] employed a non-Boussinesq approach for the buoyancydriven force in momentum equation. The laminar natural air flow inside the cavity was threedimensionally modelled. To keep the hot and cold walls in an isothermal situation, Corvaro 
and Paroncini [22] used two thermostatic baths to circulate the working fluid with a constant temperature. Turbulent natural convection inside a water-filled cavity with a high aspect ratio was numerically studied by Kizildag, Rodríguez, Oliva and Lehmkuhl [23]. The Rayleigh number was chosen to be above $10^{11}$ in their study. They explained that applying a nonBoussinesq approach for density may improve the results. On the other hand, no reports were found for an EG-water mixture inside a cavity, and most of the studies were recently numerically focused on the mixture of EG and ultrafine particle systems [24, 25].

The literature review shows that much research in natural convection cavity flow is focused on air-filled cavities, and only a few experimental works are available on water-filled cavities. There are no reports for an EG-water mixture. A large part of the numerical analysis of the cavity was also conducted on two-dimensional models. Therefore, a comparison study on the nature of the flow inside a cavity with these fluids would be worthwhile for future work. The main aim of this paper is to experimentally and numerically compare the nature of the water and EG-water flow in the cavity. The simulation results for air-filled cavities are also presented for further discussion. The range of Rayleigh numbers is in the order of $10^{8}$ for water and EG-water, which shows that all the tests were conducted in the laminar regime.

\section{Experimental instrumentation}

Figure 1 illustrates the schematic and arrangement of the experimental setup used in this study. The cavity can be seen in the middle. It has an aspect ratio of 0.94 and is $96 \mathrm{~mm} \times 120 \mathrm{~mm}$ in size (in the $\mathrm{Y}$ and $\mathrm{Z}$ directions respectively) for the differentially heated walls. The distance between the hot and cold walls is $102 \mathrm{~mm}$ (in the $\mathrm{X}$ direction). The other walls of the cavity are insulated. Two novel shell and tube counter flow heat exchangers were designed for this research and presented as the diabatic walls to produce a constant temperature. The fabricated material in all parts of the heat exchangers is copper, with polyvinyl chloride (PVC) plates placed on the other walls and the lid of the cavity. The size of the rectangular box of the heat exchanger (or shell) is $96 \mathrm{~mm} \times 120 \mathrm{~mm} \times 18 \mathrm{~mm}$. The hydraulic diameter of the shell is almost equal to the tube to split the total mass flow rate between them adequately. As a result, a better distribution of temperature on the diabatic walls would be expected. The inside diameter of the tube is $10.7 \mathrm{~mm}$ and the wall is $1 \mathrm{~mm}$ thick. Two copper plates $2 \mathrm{~mm}$ thick on the sides and another plate $4 \mathrm{~mm}$ thick in the middle were mounted in each heat exchanger to form the shell. The thickness of the hot and cold walls of the heat exchangers in the cavity is also $4 \mathrm{~mm}$.

The constant temperature of the hot and cold heat exchangers was supplied by two Polyscience thermostatic circulating baths (PD20R). Distilled water was used as the working fluid in both baths. The volume flow rate and constant flow temperature investigated in this research ranged from 0.0141 to $0.0324 \mathrm{lit} / \mathrm{s}$ and $5{ }^{\circ} \mathrm{C}$ to $70{ }^{\circ} \mathrm{C}$ respectively. The baths provided these values.

All the visible surfaces in Figure 1c were covered with a $20 \mathrm{~mm}$-thick insulator made of polystyrene. Then, the setup was placed in a bigger wooden box filled with the same insulator. The thermocouples (part number TT-T-30-SLE(ROHS)) used in the experiments were supplied by Omega Engineering Inc. and had an American wire gauge (AWG) diameter of 30. Three thermocouples were placed at the face of each heat exchanger in the cavity to measure the temperature of the cold and the hot walls at the top, middle and bottom (as shown in Figure 1c). To capture the temperature profile in two directions, seven 
thermocouples were placed at the mid-horizontal line of the cavity towards the $\mathrm{X}$-axis from the hot to the cold wall. Five thermocouples were placed at the mid-vertical line towards the Y-axis from the bottom to the top of the insulated horizontal walls.

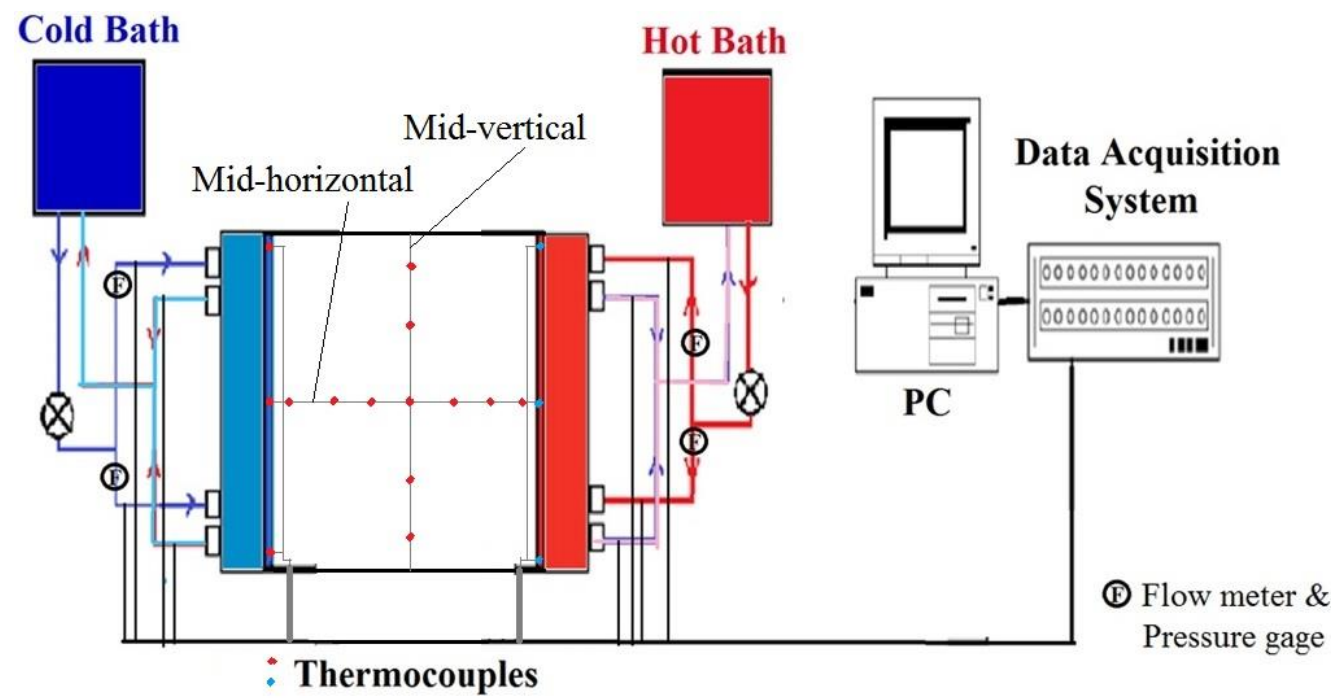

a)

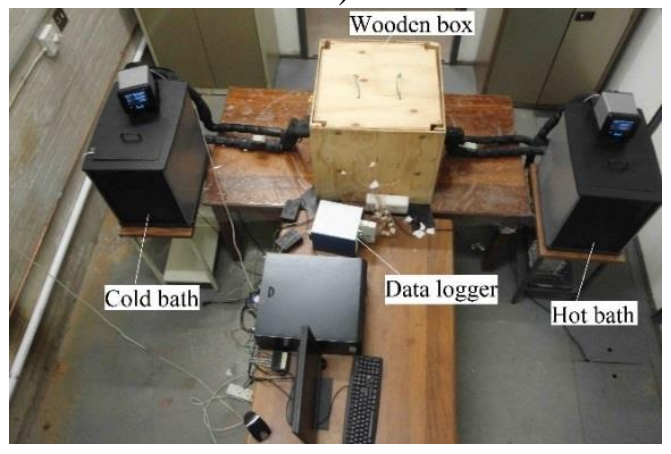

b)

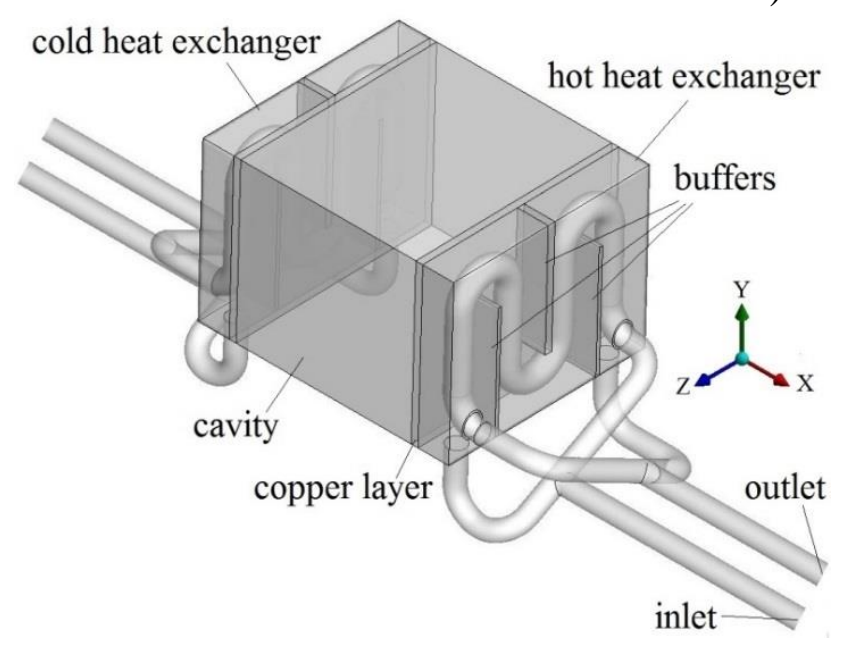

c)

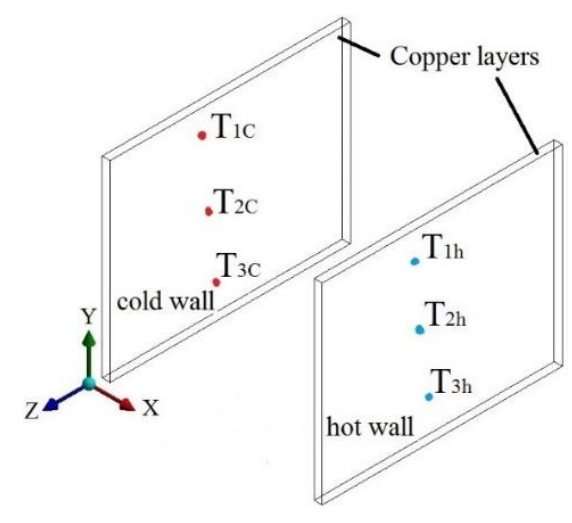

d) Positions of thermocouples attached to the hot (h) and cold (c) walls

Figure 1: Test section including heat exchangers and cavity

A temperature data logger was employed to measure the inlet and outlet temperatures of the heat exchangers. Therefore, two thermocouples were placed at the inlet and outlet of each heat exchanger to calculate the amount of heat transfer by $\dot{m} c_{p} \Delta\left(T_{\text {out }}-T_{\text {in }}\right)$. 
The temperature measurement on the outer surfaces of the insulators shows that the percentage of heat loss to the ambient temperature is less than $3 \%$ in most cases.

Due to the accuracy of the constant temperature of the bath device with the precision of $\pm 0.005^{\circ} \mathrm{C}$, all thermocouples were calibrated with an accuracy of $\pm 0.02{ }^{\circ} \mathrm{C}$. The temperature was recorded by the data acquisition system that was incorporated by the Labview software. The duration of each test was based on reaching a steady-state condition, while the temperature fluctuation was less than $0.1 \%$. It occurred after almost 90 minutes from the beginning in most of the tests.

\section{Flow equations, CFD approach and thermo-physical properties}

The entire test section, including two heat exchangers and the cavity, is simulated in this research. The geometry of the model can be seen in Figure 1c. The geometry is complex due to the fact that there are three different types of flow in the model when a test gets steady. The hot heat exchanger carries turbulent flow with a Reynolds number above 3500 . The cold section deals with the laminar regime, which has a Reynolds number less than 2200 . The laminar natural convection inside the cavity has a Rayleigh number around $10^{8}$ for water and EG-water and $10^{6}$ for air. The Rayleigh number is defined as:

$$
R a=\frac{g \beta L^{3}\left(T_{h}-T_{c}\right)}{\alpha v},
$$

where $L$ is the distance between the hot wall (with a temperature of $T_{h}$ ) and the cold wall (with a temperature of $T_{c}$ ) in the cavity. The thermo-physical properties are calculated in terms of the average temperature $\left(T_{h}+T_{c}\right) / 2$. The governing equations are those for continuity, momentum and energy, and are as follows:

$$
\begin{aligned}
& \frac{\partial \bar{u}_{i}}{\partial x_{i}}=0 \\
& \rho(T) u_{j} \frac{\partial \bar{u}_{i}}{\partial x_{j}}=-\frac{\partial \bar{P}}{\partial x_{i}}+\frac{\partial}{\partial x_{j}}\left[\mu \frac{\partial \bar{u}_{i}}{\partial x_{j}}-\rho \overline{u_{i}^{\prime} u_{j}^{\prime}}\right]+g_{i} \rho(T) \\
& \rho \bar{u}_{j} \frac{\partial \bar{T}}{\partial x_{j}}=\frac{1}{c_{P}} \frac{\partial}{\partial x_{j}}\left[k \frac{\partial \bar{T}}{\partial x_{j}}-\rho c_{P} \overline{T^{\prime} u_{j}^{\prime}}\right]
\end{aligned}
$$

The perturbation or fluctuating terms introduced by $u_{j}^{\prime}$ and $T^{\prime}$ show that they are neglected when the flow inside the cavity and the cold heat exchanger is solved. The fluctuating part of velocity and turbulent viscosity is modelled by the Realisable $k-\varepsilon$ model because of its robustness for complicated geometries like heat exchangers [26, 27]. The transport equations for turbulent kinetic energy $k$ and dissipation rate $\varepsilon$ are as follows:

$$
\begin{aligned}
& \frac{\partial}{\partial x_{i}}\left(\rho k_{t} u_{i}\right)=\frac{\partial}{\partial x_{i}}\left(\left[\mu+\frac{\mu_{t}}{\sigma_{k}}\right] \frac{\partial k_{t}}{\partial x_{i}}\right)+G_{k}+G_{b}-\rho \varepsilon-Y_{M}+S_{k} \\
& \frac{\partial}{\partial x_{i}}\left(\rho \varepsilon u_{i}\right)=\frac{\partial}{\partial x_{i}}\left(\left[\mu+\frac{\mu_{t}}{\sigma_{\varepsilon}}\right] \frac{\partial \varepsilon}{\partial x_{i}}\right)+\rho C_{1} S \varepsilon-\rho C_{2} \frac{\varepsilon^{2}}{k_{t}+\sqrt{v \varepsilon}}+C_{1 \varepsilon} \frac{\varepsilon}{k_{t}} C_{3 \varepsilon} G_{b}+S_{\varepsilon} \\
& \mu_{t}=\rho C_{\mu} \frac{k_{t}^{2}}{\varepsilon}
\end{aligned}
$$


More details on the coefficients and source terms can be found in the ANSYS-FLUENT user manual [28]. The thermo-physical and transport properties are set to be functions of temperature. Instead of using the Boussinesq approach for density with the linear function of temperature in the $\mathrm{Y}$-direction as $\beta \Delta \mathrm{T}$, a non-Boussinesq term was employed for natural convection inside the cavity with density as the second polynomial function of temperature. A proper curve fitting was applied to provide all the thermo-physical and transport properties in terms of temperature. The required data and tables were borrowed from Kröger [29] for air and water, and from the American Society of Heating, Refrigerating and Air-conditioning Engineers (ASHRAE) [30] for EG-water. Table 1 lists the properties as a function of temperature.

Table 1: Thermo-physical properties of water, air and EG-water

\begin{tabular}{clcll}
\hline & $\rho\left(k g / m^{3}\right)$ & $c_{p}(J / k g . k)$ & $k(W / m . k)$ & $\mu(k g / m . s)$ \\
\hline Water & $765.33+1.8142 \times \mathrm{T}$ & $(28.07-0.2817 \times \mathrm{T}$ & $-0.5752+0.006397 \times \mathrm{T}$ & $0.0967-8.207 \mathrm{e}-4 \times \mathrm{T}$ \\
& $-0.0035 \times \mathrm{T}^{2}$ & $+0.00125 \times \mathrm{T}^{2}$ & $-8.151 \mathrm{e}-6 \times \mathrm{T}^{2}$ & $+2.344 \mathrm{e}-6 \times \mathrm{T}^{2}$ \\
& & $-2.48 \mathrm{e}-6 \times \mathrm{T}^{3}$ & & $-2.244 \mathrm{e}-9 \times \mathrm{T}^{3}$ \\
& & $\left.+1.857 \mathrm{e}-9 \times \mathrm{T}^{4}\right) \times 1000$ & & \\
\hline Air & $3.41500963-$ & $1037.3734926-$ & $0.00324027+$ & $4.834032 \mathrm{e}-6+$ \\
& $0.01097795 \times \mathrm{T}$ & $0.2384454 \times \mathrm{T}$ & $7.655988 \mathrm{e}-5 \times \mathrm{T}$ & \\
& $+1.1724 \mathrm{e}-5 \times \mathrm{T}^{2}$ & $+0.0004568 \times \mathrm{T}^{2}$ & & \\
& & & & \\
\hline EG-water & $1009.77+$ & $1877.53+$ & $-0.0995663+$ & $\mathrm{T}$ \\
& $0.963902 \times \mathrm{T}$ & $4.25635 \times \mathrm{T}$ & $0.00244759 \times \mathrm{T}$ & $0.011411192 \times \mathrm{T}$ \\
& $-0.024296 \times \mathrm{T}^{2}$ & & $-3.22739 \mathrm{e}-6 \times \mathrm{T}^{2}$ & $+3.4359335 \mathrm{e}-5 \times \mathrm{T}^{2}$ \\
& & & & $-3.460286 \mathrm{e}-8 \times \mathrm{T}^{3}$
\end{tabular}

Temperature is expressed in Kelvin.

\subsection{Numerical models and boundary conditions}

Because of the high complexity of the fluid flow and geometry in this study, segregated solvers such as the Semi-Implicit Method for Pressure-Linked Equations (SIMPLE) algorithm cannot converge easily for time-averaged Navier-Stokes equations. Therefore, a coupled algorithm was employed via the CFD commercial code of ANSYS-FLUENT 15.0. This iteratively solves both momentum- and pressure-based continuity equations at the same time. The effects of gravity are included due to the buoyancy force inside the cavity.

The grid generated for the tube and shell of the heat exchangers is shown in Figure 2. Unstructured meshes were assigned for the heat exchangers, and non-uniform structured meshes for the cavity and copper layers. The closest node to the walls was chosen to be $0.2 \mathrm{~mm}$. Since the heat was transferred from the hot heat exchanger, passing through the cavity by natural convection, and finally leaving from the cold heat exchanger, it is timeconsuming to iteratively reach heat balance in the model. Thus, the balance of heat transfer in the domain was chosen to be the main criterion. The grid study was conducted by trying a different number of nodes in the model. The final number of cells was chosen to be 912081 unstructured cells for the heat exchanger and 226981 structured cells for the cavity, with 2078644 cells in total. Table 2 explains the grid study's details for some cases of waterfilled cavities compared with the results of the chosen grid. 


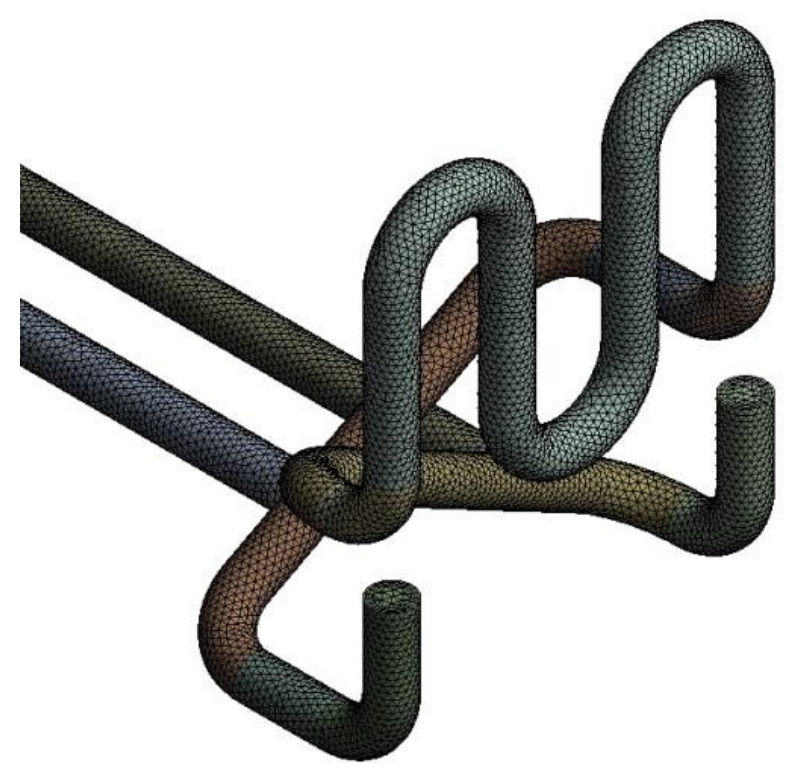

a)

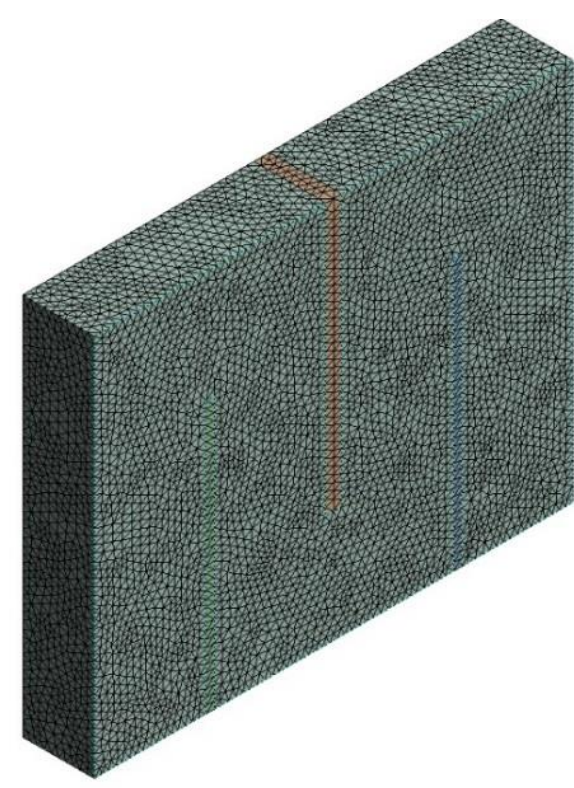

b)

Figure 2: The generated mesh for the tube and shell part of the heat exchanger (unstructured)

Table 2: Grid study of numerical simulation

\begin{tabular}{ccccc}
\hline Test case & $\begin{array}{c}\text { Number of cells for the heat } \\
\text { exchanger }\end{array}$ & $\begin{array}{c}\text { Number of cells for the } \\
\text { cavity }\end{array}$ & Total cells & Heat flux error from chosen grid \\
\hline 1 & 413578 & 91125 & 931431 & $9 \%$ \\
\hline 2 & 912081 & 226981 & 2078644 & $0 \%$ \\
\hline 3 & 1325421 & 421875 & 3111168 & $-0.9 \%$ \\
\hline 4 & 1968780 & 912673 & 4937765 & $-1.2 \%$ \\
\hline
\end{tabular}

Uniform velocity and temperature distribution were applied to the inlet of both heat exchangers, while the exit boundary condition in the tubes was the chosen pressure outlet. All the visible regions, including the outer surfaces of the tubes, shells and cavity, were assumed to be at zero heat flux or insulated. As expected with the same inlet conditions, the type of fluid inside the cavity will lead the pattern of heat transfer and flow structure in the cavity and heat exchangers. Comparing these features with three common types of fluid is the main goal of this research.

Table 3: Measurements for laminar natural convection in an air-filled cavity

\begin{tabular}{|c|c|c|c|c|c|c|}
\hline Test & $T_{c \text {-wall }}\left({ }^{o} C\right)$ & $T_{h \text {-wall }}\left({ }^{\circ} C\right)$ & $T_{c}\left({ }^{o} C\right)$ & $T_{h}\left({ }^{o} C\right)$ & $\Delta T\left({ }^{\circ} C\right)$ & $R a$ \\
\hline \multicolumn{7}{|c|}{ Air-filled cavity } \\
\hline 1 & $\begin{array}{l}T_{1 c}=21.6 \\
T_{2 c}=21.31 \\
T_{3 c}=21.26\end{array}$ & $\begin{array}{l}T_{l h}=39.63 \\
T_{2 h}=39.59 \\
T_{3 h}=39.24\end{array}$ & 21.42 & 39.48 & 18.06 & $1.7 \times 10^{6}$ \\
\hline 2 & $\begin{array}{l}T_{l c}=15.4 \\
T_{2 c}=14.77 \\
T_{3 c}=14.6\end{array}$ & $\begin{array}{l}T_{1 h}=49.25 \\
T_{2 h}=49.2 \\
T_{3 h}=48.27\end{array}$ & 14.92 & 48.9 & 33.98 & $3.14 \times 10^{6}$ \\
\hline 3 & $\begin{array}{l}T_{1 c}=8.88 \\
T_{2 c}=8.5 \\
T_{3 c}=8.24\end{array}$ & $\begin{array}{l}T_{1 h}=39.69 \\
T_{2 h}=39.56 \\
T_{3 h}=39.29\end{array}$ & 8.54 & 39.51 & 30.97 & $3.24 \times 10^{6}$ \\
\hline 4 & $\begin{array}{l}T_{l c}=10.94 \\
T_{2 c}=10.12 \\
T_{3 c}=9.82\end{array}$ & $\begin{array}{l}T_{1 h}=54.01 \\
T_{2 h}=54.04 \\
T_{3 h}=52.86\end{array}$ & 10.29 & 53.64 & 43.31 & $4.16 \times 10^{6}$ \\
\hline 5 & $\begin{array}{l}T_{1 c}=9.1 \\
T_{2 c}=8.28 \\
T_{3 c}=7.95\end{array}$ & $\begin{array}{l}T_{1 h}=58.88 \\
T_{2 h}=58.78 \\
T_{3 h}=57.08\end{array}$ & 8.46 & 58.24 & 49.78 & $4.52 \times 10^{6}$ \\
\hline
\end{tabular}

$\mathrm{T}_{\mathrm{c} \text {-wall }}$ and $\mathrm{T}_{\mathrm{h} \text {-wall }}$ are the measured temperatures on the cold and hot walls of the cavity respectively. $T_{c}$ and $T_{h}$ are the average temperature of $\mathrm{T}_{\mathrm{c} \text {-wall }}$ and $\mathrm{T}_{\mathrm{h} \text {-wall }}$ respectively. $\Delta T_{\text {ave }}$ is the difference between the average temperatures on the hot and cold walls $\left(T_{c}-T_{h}\right)$. 


\section{Results and discussion}

To ensure that the heat exchangers can provide uniformly constant temperature walls, early tests were conducted with an air-filled cavity, which is presented in Table 3 . The maximum deviation in temperature on each wall was about $1{ }^{\circ} \mathrm{C}$ in tests 4 and 5 , and less than $1{ }^{\circ} \mathrm{C}$ in other tests, which can generally be assumed to be isothermal.

Since this study mainly focuses on the comparison between a water-filled and an EG-waterfilled cavity, the results of the experiments are explained in Table 4.

The average Nusselt number is expressed as follows:

$$
\overline{N u}=\frac{q^{\prime \prime} L}{k\left(T_{h}-T_{c}\right)},
$$

where $q^{\prime \prime}, T_{h}, T_{c}$ and $k$ represent heat flux, the average temperature of the hot and cold walls of the cavity, and the thermal conductivity of the fluid respectively.

Table 4: Measurements for laminar natural convection inside a cavity

\begin{tabular}{|c|c|c|c|c|c|c|c|c|}
\hline Test & $T_{c \text {-wall }}\left({ }^{o} C\right)$ & $T_{h \text {-wall }}\left({ }^{o} C\right)$ & $T_{c}\left({ }^{o} C\right)$ & $T_{h}\left({ }^{o} C\right)$ & $\Delta T\left({ }^{\circ} C\right)$ & $R a$ & $\overline{N u}-\exp$ & $\overline{N u}-n u m$ \\
\hline \multicolumn{9}{|c|}{ Water-filled cavity } \\
\hline 1 & $\begin{array}{l}T_{1 c}=25.33 \\
T_{2 c}=24.53 \\
T_{3 c}=23.9\end{array}$ & $\begin{array}{l}T_{l h}=33.84 \\
T_{2 h}=33.22 \\
T_{3 h}=33.08\end{array}$ & 24.56 & 33.38 & 8.81 & $2.27 \times 10^{8}$ & 41.14 & 41.68 \\
\hline 2 & $\begin{array}{l}T_{1 c}=17.03 \\
T_{2 c}=15.5 \\
T_{3 c}=13.68\end{array}$ & $\begin{array}{l}T_{l h}=35.82 \\
T_{2 h}=34.34 \\
T_{3 h}=34.1\end{array}$ & 15.4 & 34.75 & 19.35 & $4.07 \times 10^{8}$ & 52.1 & 49.5 \\
\hline 3 & $\begin{array}{l}T_{1 c}=25.15 \\
T_{2 c}=23.56 \\
T_{3 c}=21.52\end{array}$ & $\begin{array}{l}T_{1 h}=44.93 \\
T_{2 h}=43.23 \\
T_{3 h}=42.91\end{array}$ & 23.41 & 43.68 & 20.27 & $6.29 \times 10^{8}$ & 59.5 & 55.8 \\
\hline 4 & $\begin{array}{l}T_{1 c}=23.77 \\
T_{2 c}=21.91 \\
T_{3 c}=19.06\end{array}$ & $\begin{array}{l}T_{1 h}=48.85 \\
T_{2 h}=46.66 \\
T_{3 h}=46.28\end{array}$ & 21.58 & 47.26 & 25.68 & $8.14 \times 10^{8}$ & 63.73 & 60.01 \\
\hline 5 & $\begin{array}{l}T_{1 c}=24.44 \\
T_{2 c}=22.27 \\
T_{3 c}=18.88\end{array}$ & $\begin{array}{l}T_{l h}=53.25 \\
T_{2 h}=50.75 \\
T_{3 h}=50.48\end{array}$ & 21.86 & 51.49 & 29.62 & $1.13 \times 10^{9}$ & 67.6 & 64.5 \\
\hline \multicolumn{9}{|c|}{ EG-water cavity } \\
\hline 1 & $\begin{array}{l}T_{1 c}=24.1 \\
T_{2 c}=23.23 \\
T_{3 c}=22.76\end{array}$ & $\begin{array}{l}T_{l h}=34.71 \\
T_{2 h}=34.2 \\
T_{3 h}=33.86\end{array}$ & 23.36 & 34.25 & 10.88 & $1.94 \times 10^{8}$ & 35.52 & 37.4 \\
\hline 2 & $\begin{array}{l}T_{1 c}=14.7 \\
T_{2 c}=12.83 \\
T_{3 c}=11.63\end{array}$ & $\begin{array}{l}T_{l h}=37.09 \\
T_{2 h}=35.9 \\
T_{3 h}=35.11\end{array}$ & 13.05 & 36.03 & 22.98 & $3.52 \times 10^{8}$ & 52.2 & 47.8 \\
\hline 3 & $\begin{array}{l}T_{1 c}=22.77 \\
T_{2 c}=20.49 \\
T_{3 c}=19.05\end{array}$ & $\begin{array}{l}T_{l h}=46.56 \\
T_{2 h}=45.41 \\
T_{3 h}=44.38\end{array}$ & 20.77 & 45.45 & 24.68 & $5.14 \times 10^{8}$ & 56 & 52.7 \\
\hline 4 & $\begin{array}{l}T_{1 c}=20.63 \\
T_{2 c}=17.96 \\
T_{3 c}=16.05\end{array}$ & $\begin{array}{l}T_{1 h}=50.56 \\
T_{2 h}=48.84 \\
T_{3 h}=47.73\end{array}$ & 18.21 & 49.04 & 30.83 & $6.5 \times 10^{8}$ & 61.8 & 56.8 \\
\hline 5 & $\begin{array}{l}T_{1 c}=20.17 \\
T_{2 c}=17.04 \\
T_{3 c}=14.78\end{array}$ & $\begin{array}{l}T_{l h}=54.91 \\
T_{2 h}=52.97 \\
T_{3 h}=51.67\end{array}$ & 17.33 & 53.18 & 35.84 & $7.97 \times 10^{8}$ & 63.01 & 58.77 \\
\hline
\end{tabular}




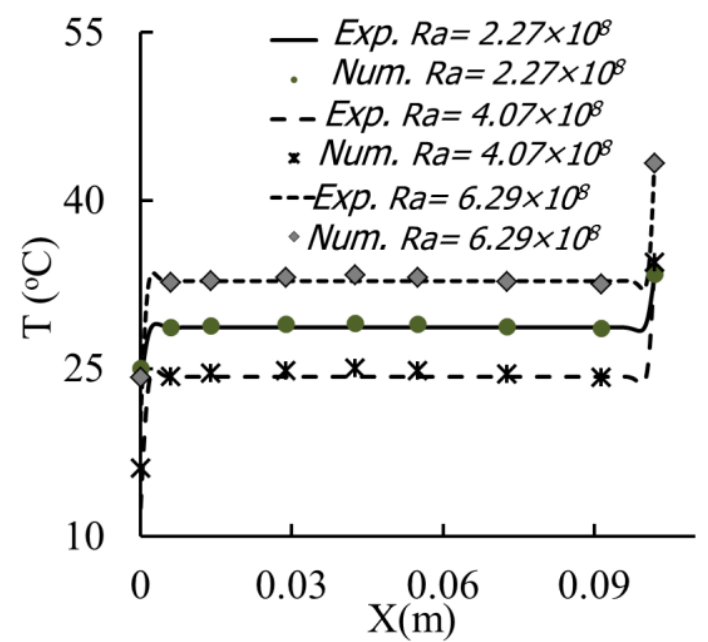

a) Water-filled cavity

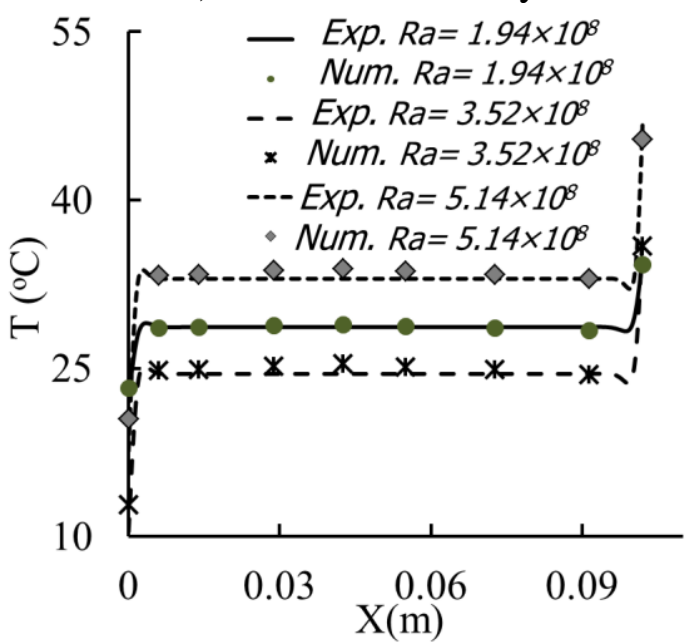

b) Cavity filled with EG-water

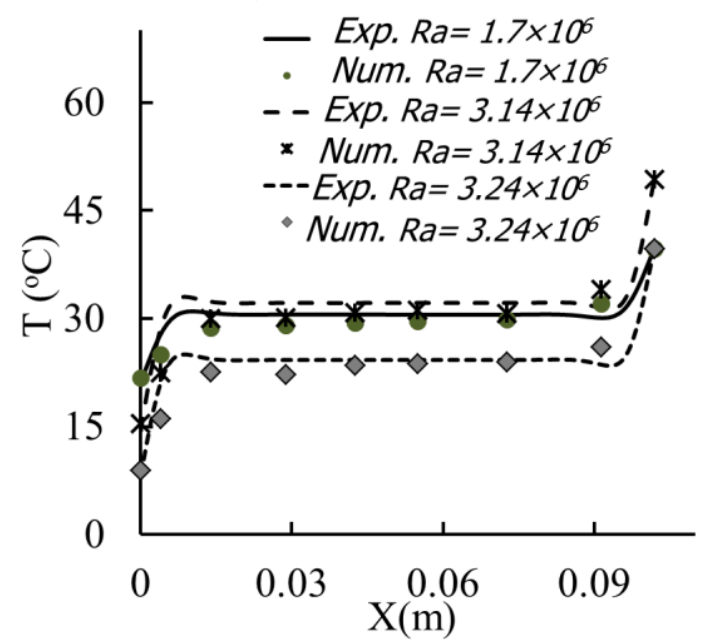

c) air-filled cavity

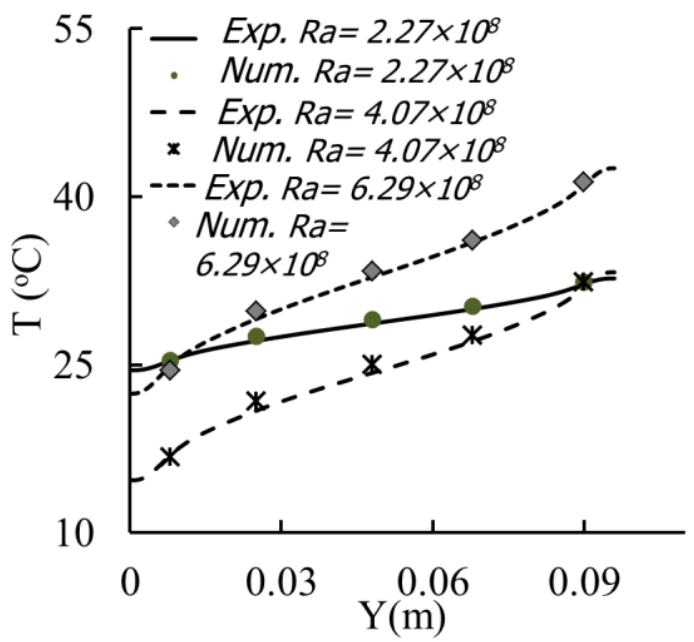

d) Water-filled cavity

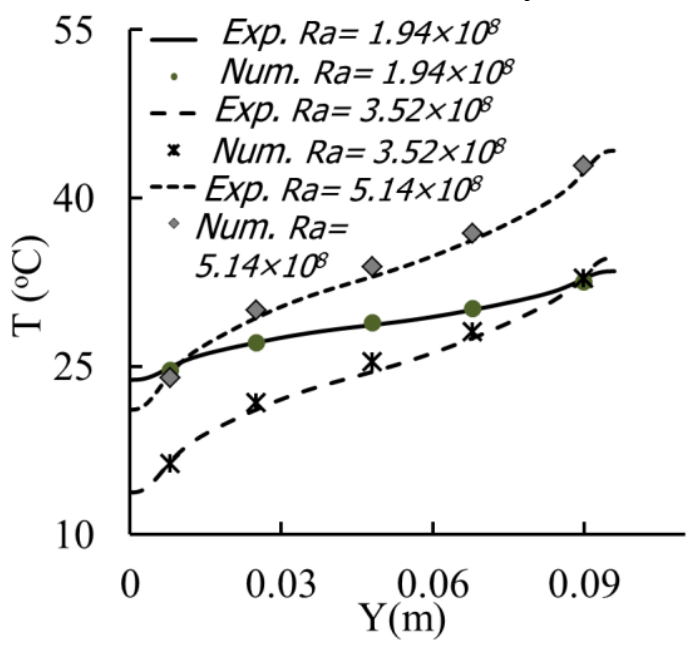

e) Cavity filled with EG-water

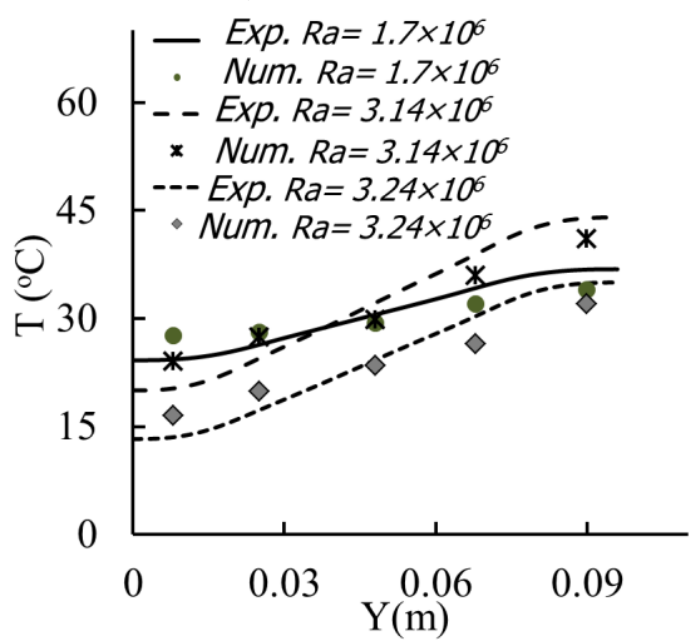

f) air-filled cavity

Figure 3: Measured and predicted temperature on the mid-horizontal line from the hot to the cold wall (left graphs) and the mid-vertical line between the insulated walls from bottom to top (right graphs)

As indicated in Table 4, it is challenging to achieve isothermal walls in the case of EG-waterfilled and pure water-filled cavities. A big gap is generated between the fluid heat resistance at the bottom and top halves of the diabatic walls, as the Rayleigh number increases. 
Therefore, the maximum temperature variation on a wall from bottom to top occurs in Test 5, which rendered the highest Rayleigh number in the tests. The variations somehow reach $5{ }^{\circ} \mathrm{C}$. However, the temperature deviation on the hot wall is less than that on the cold wall because of turbulent flow with better heat transfer in the hot heat exchanger. Calculated Nusselt numbers were also in good agreement with the measured one in the case of the EG-waterand water-filled cavities. The highest deviation occurs in the EG-water cavity with less than $7 \%$. It was also observed that the mean temperature of the hot and cold walls is equal to the temperature at the centre of the wall for all the tests. In the following paragraphs, the simulation results of water- and EG-water-filled cavities are presented and compared. For purposes of further explanation, the numerical findings of the air-filled cavity are also discussed.

The measured temperature of seven and five thermocouples placed at the mid-horizontal (X direction) and vertical lines ( $\mathrm{Y}$ direction) is compared to the estimated one from numerical simulations in Figure 3. The calculated values are in good agreement with the measurements in all the cases. The temperature profile is flat for most of the middle of the cavity for all the fluids, although the air thermal boundary layer is bigger than in the other cases. Therefore, the effects of this extensive boundary layer are propagated to the rest of the cavity, and a higher slope of the temperature profile is present in the rest of the cavity in all directions.

Figure 4 shows the flow pattern and non-dimensional distribution of temperature at a plane near the wall of the hot heat exchanger. The non-dimensional temperature is defined in terms of the temperature of the hot and cold walls of the cavity as $\left(T-T_{a v e}\right) /\left(T_{h}-T_{c}\right)$, which $T_{a v e}=$ $\left(T_{h}+T_{c}\right) / 2$. It is noted that the inlet conditions of the heat exchangers for these three types of fluids inside the cavity were kept the same. The higher gradient of temperature plots $a$ and $b$ in Figure 4 revealed no impacts on flow stream traces since the flow patterns seem similar in all three plots $(\mathrm{a}, \mathrm{b}$ and $\mathrm{c})$. The order of the temperature gradient at the Y-Z plane in the water-filled cavity in Figure $4 \mathrm{a}$ is also bigger than that of the EG-water-filled cavity. It can be explained that the mixture of EG-water has a Prandtl number higher than water as $\operatorname{Pr}_{\text {water }} \sim 5$ and $\mathrm{Pr}_{\mathrm{EG} \text {-water }}$ 30 $(\mathrm{Pr}=$ viscous diffusion/thermal diffusion, and thermal diffusion represents conduction heat transfer). It provides a better distribution of temperature at the hot-wall plane when compared to the water-filled cavity. On the other hand, air flow easily causes an isothermal wall in the cavity due to high heat resistance or low conduction and momentum transfer. It distributes heat transfer evenly in the $\mathrm{Y}$ and $\mathrm{Z}$ directions and gives uniform temperature on the walls, as shown in Figure 4c. Eventually, it can be said that the temperature distribution in the heat exchanger is mainly affected by the fluid types and flows inside the cavity. The propagation of isoterms on the surfaces of non-dimensional temperature through the shell of the heat exchanger can be observed in Figure 5. A higher temperature, which covers a large part of the heat exchanger gradient, can be observed in the water-filled cavity tests. Figure 4 shows the evolution of the heat transfer temperature from inlet to outlet. 


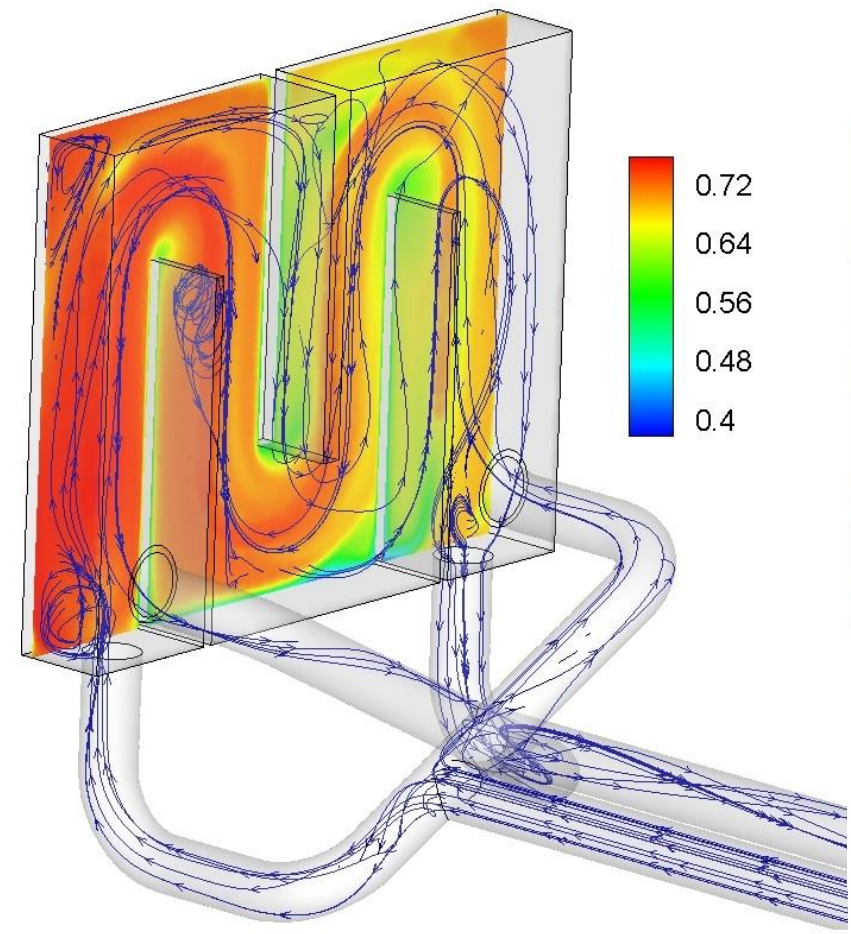

a) The hot heat exchanger next to the waterfilled cavity, $\mathrm{Ra}=6.29 \times 10^{8}$

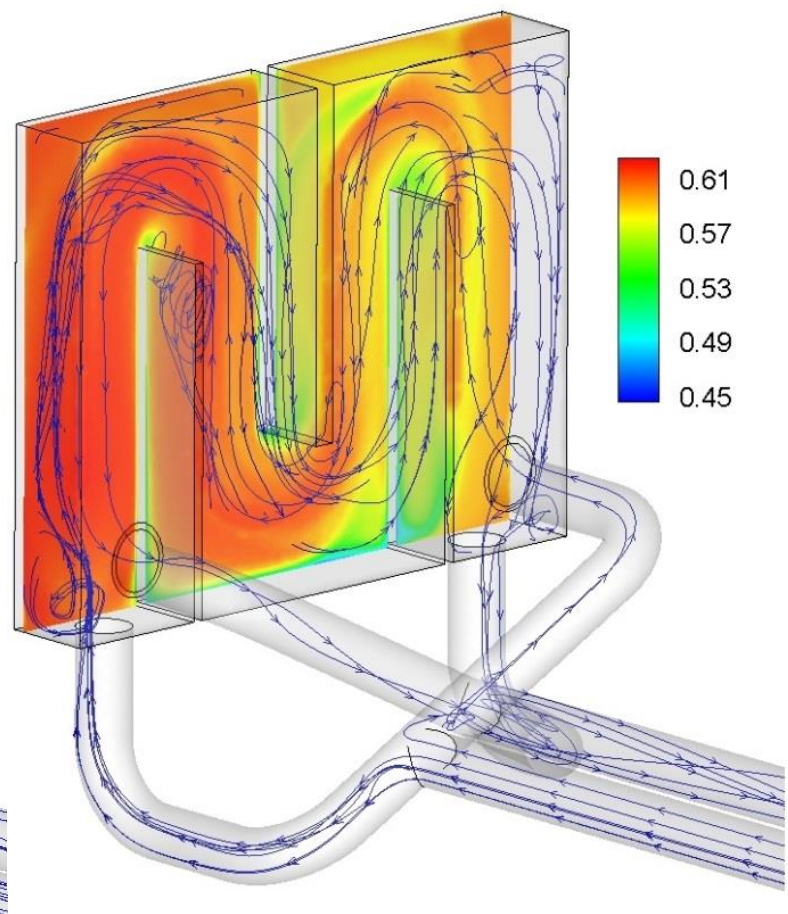

b) The hot heat exchanger next to the EGwater-filled cavity, $\mathrm{Ra}=5.14 \times 10^{8}$

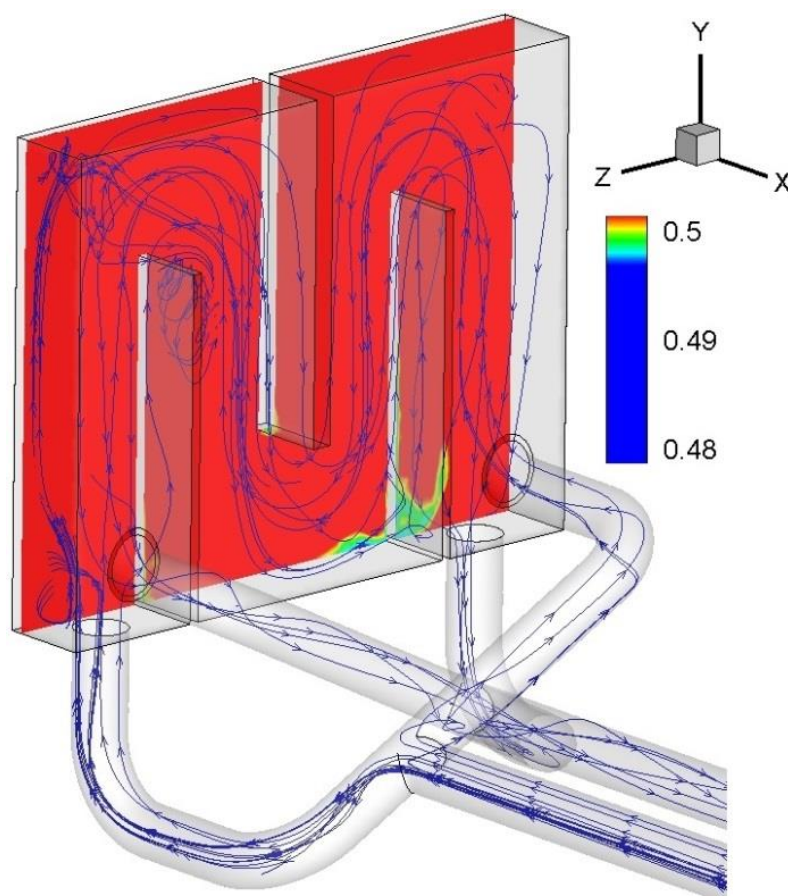

c) The hot heat exchanger next to the air-filled cavity, $\mathrm{Ra}=3.14 \times 10^{6}$

Figure 4: Stream traces and non-dimensional temperature on a plane close to the wall in the hot heat exchanger 


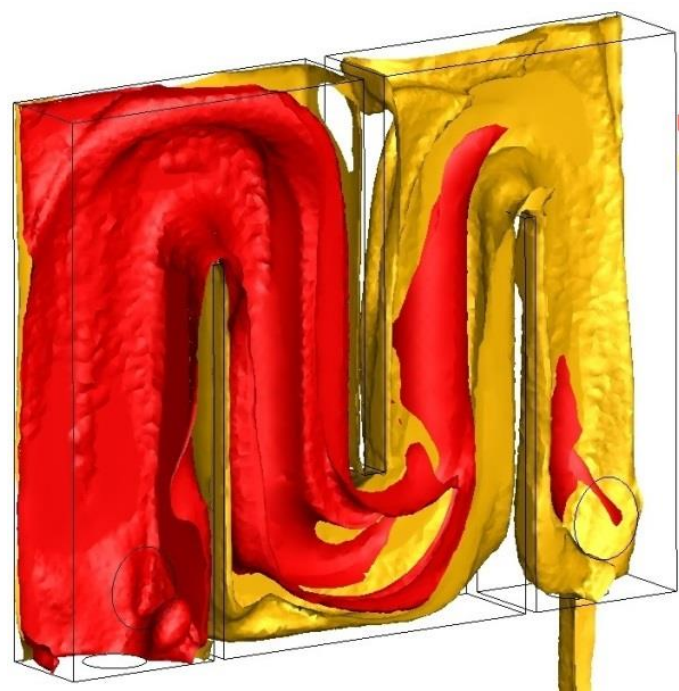

a) The hot heat exchanger next to the waterfilled cavity, $\mathrm{Ra}=1.13 \times 10^{9}$

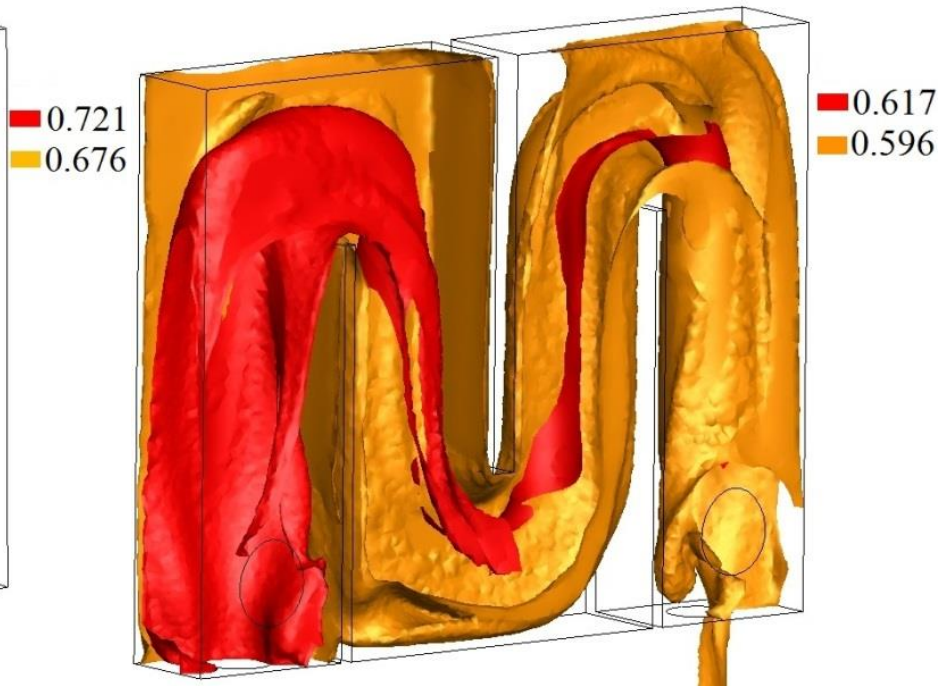

b) The hot heat exchanger next to the EGwater-filled cavity, $\mathrm{Ra}=7.97 \times 10^{8}$

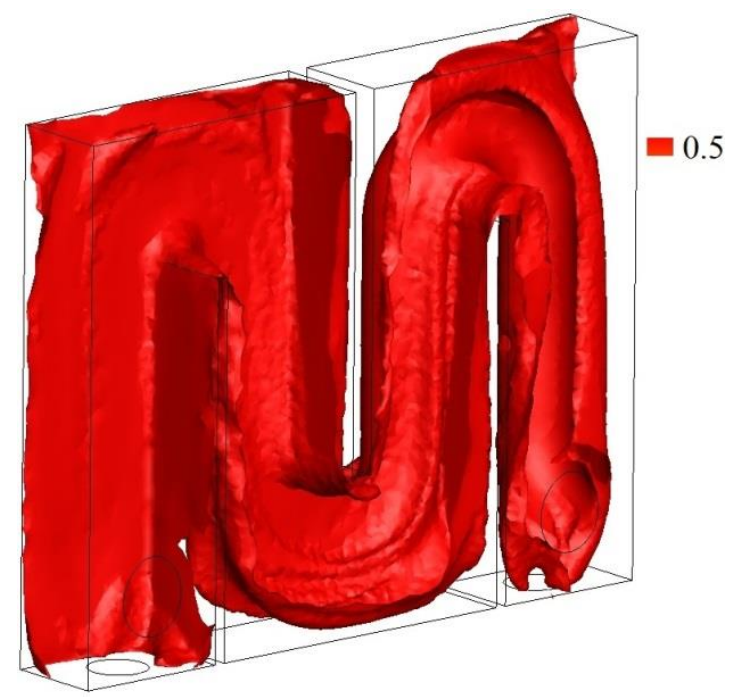

c) The hot heat exchanger next to air-filled cavity, $\mathrm{Ra}=4.52 \times 10^{6}$

\section{Figure 5: Non-dimensional isothermal surfaces in the hot heat exchanger next to the} cavity

The contours of non-dimensional temperature for both the hot and the cold walls are presented in Figure 6. The patterns of distribution are almost similar for all the fluids; however, the order of magnitude is the highest and lowest in the hot and cold walls of the water-filled cavity respectively. Since heat transfer leaves the cavity at the cold wall, the nondimensional temperature or temperature gradient was calculated as negative via the proper definition of non-dimensional temperature. The uniform distribution of temperature can also be clearly seen at the hot and cold walls of the air-filled cavity. 


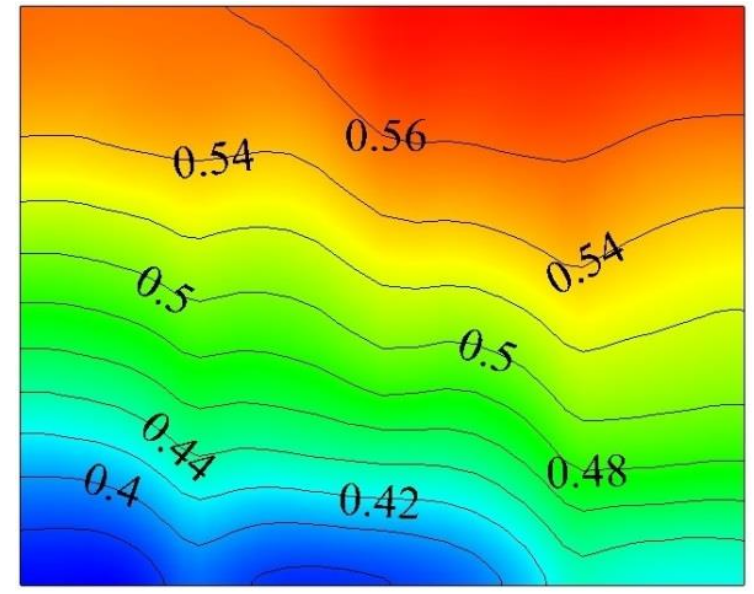

a) The hot wall of the water-filled cavity, $\mathrm{Ra}=8.14 \times 10^{8}$

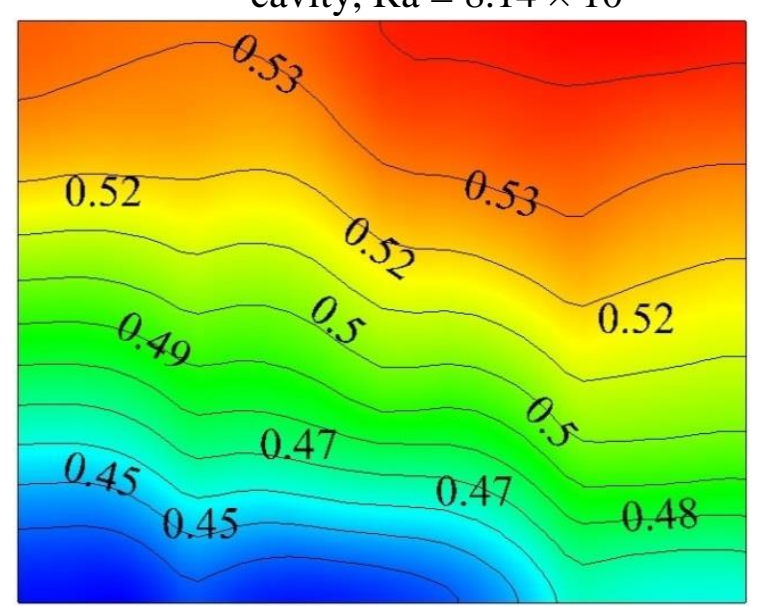

b) The hot wall of the EG-water-filled cavity, $\mathrm{Ra}=6.5 \times 10^{8}$

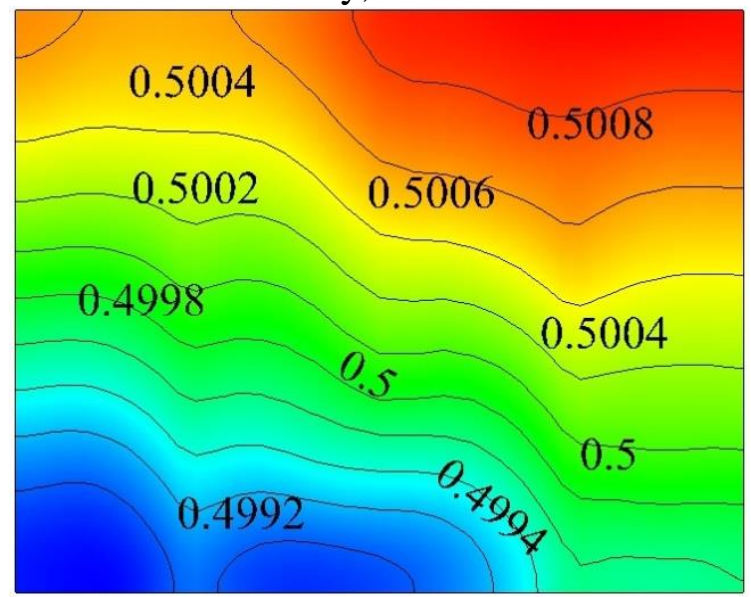

d) The hot wall of the air-filled cavity, $\mathrm{Ra}=4.16 \times 10^{6}$

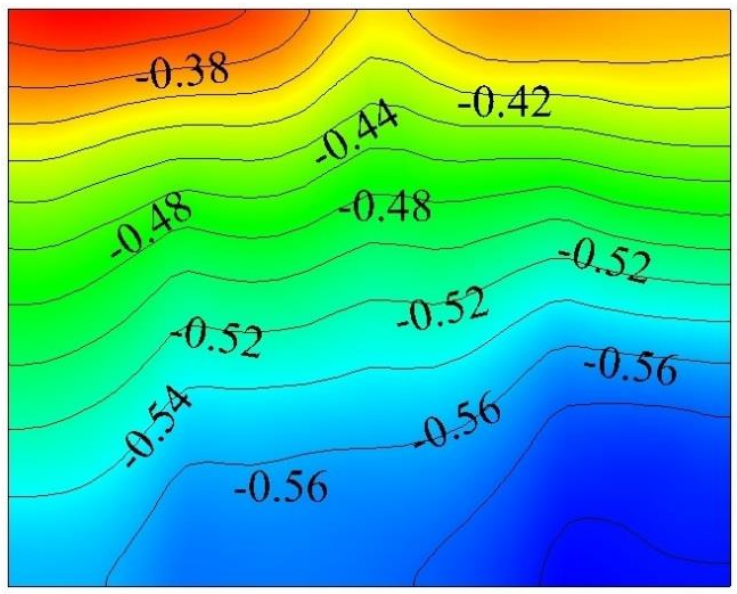

d) The cold wall of the water-filled cavity, $\mathrm{Ra}=8.14 \times 10^{8}$

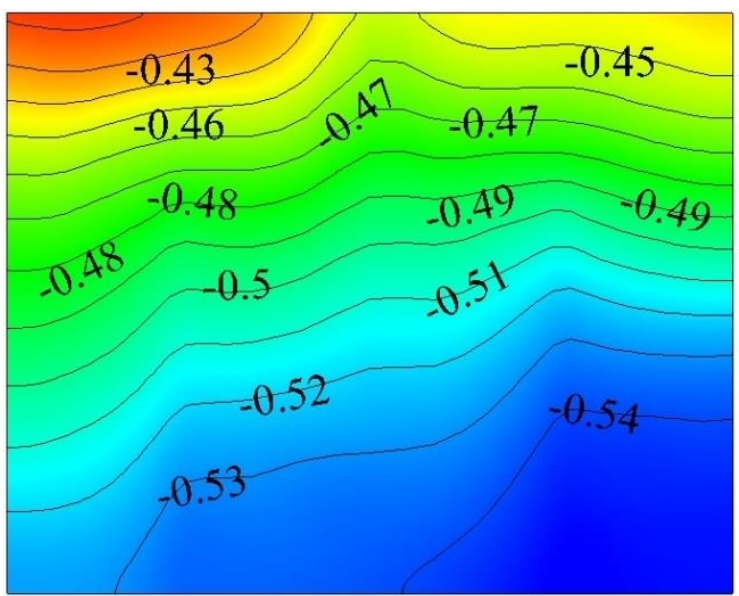

c) The cold wall of the EG-water-filled cavity, $\mathrm{Ra}=6.5 \times 10^{8}$

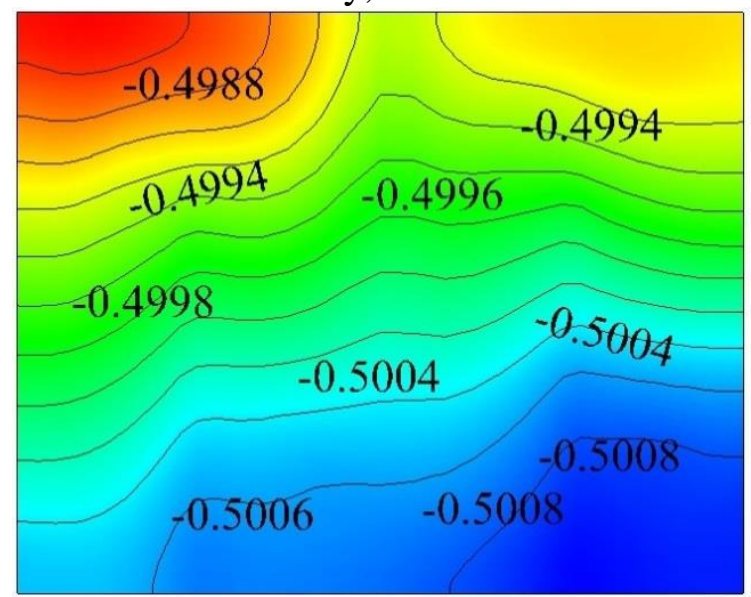

The cold wall of the air-filled cavity, $\mathrm{Ra}=4.16 \times 10^{6}$

Figure 6: Distribution of non-dimensional temperature and isothermal lines at the hot and cold walls of the cavity with different fluids 


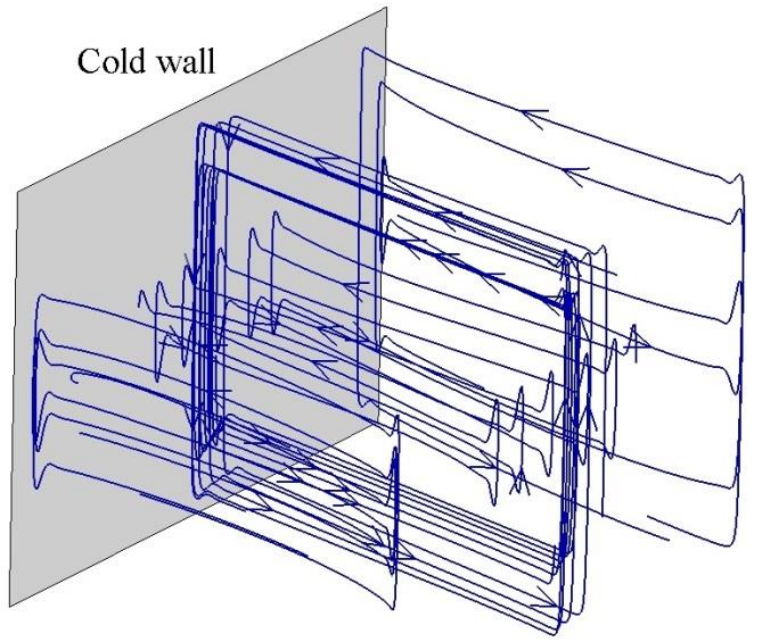

a) The water-filled cavity, $\mathrm{Ra}=1.13 \times 10^{9}$

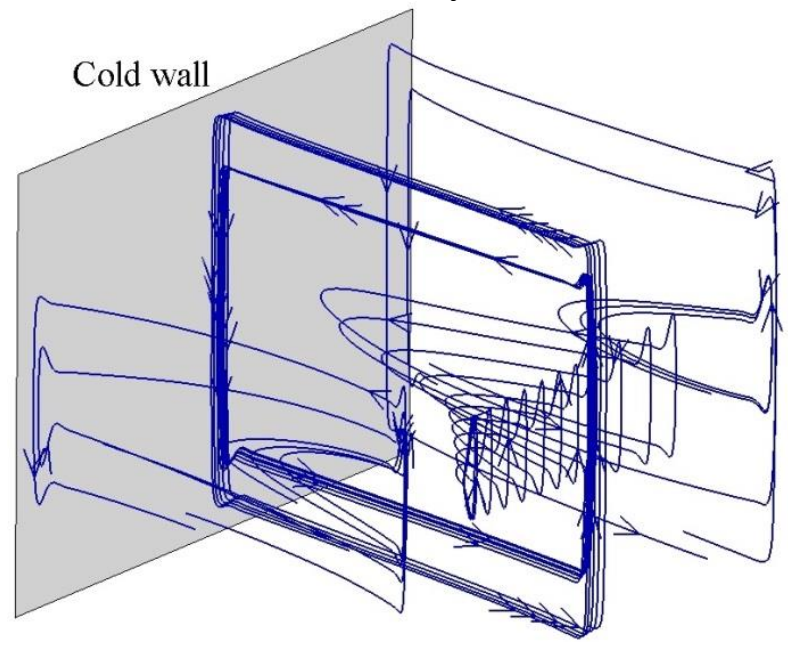

b) The EG-water-filled cavity, $\mathrm{Ra}=7.97 \times 10^{8}$

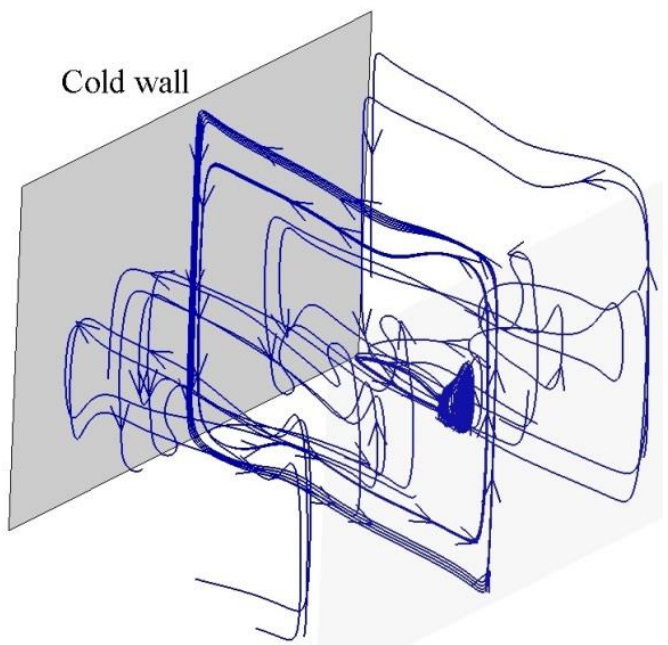

c) The air-filled cavity, $\mathrm{Ra}=4.52 \times 10^{6}$

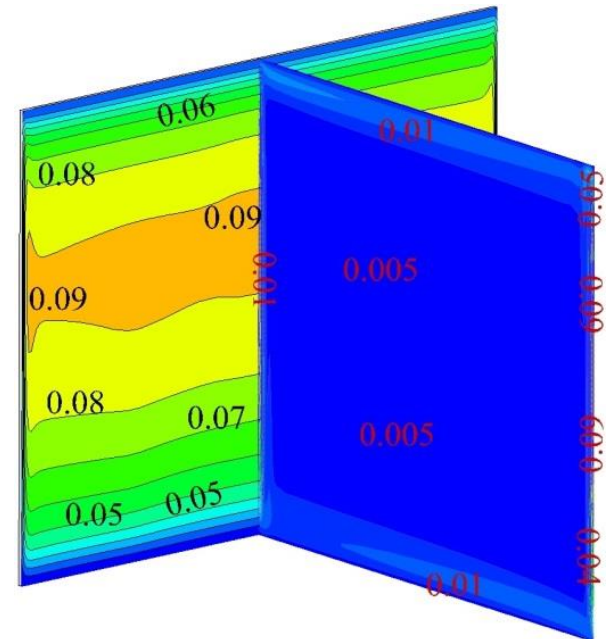

d) The water-filled cavity, $\mathrm{Ra}=1.13 \times 10^{9}$

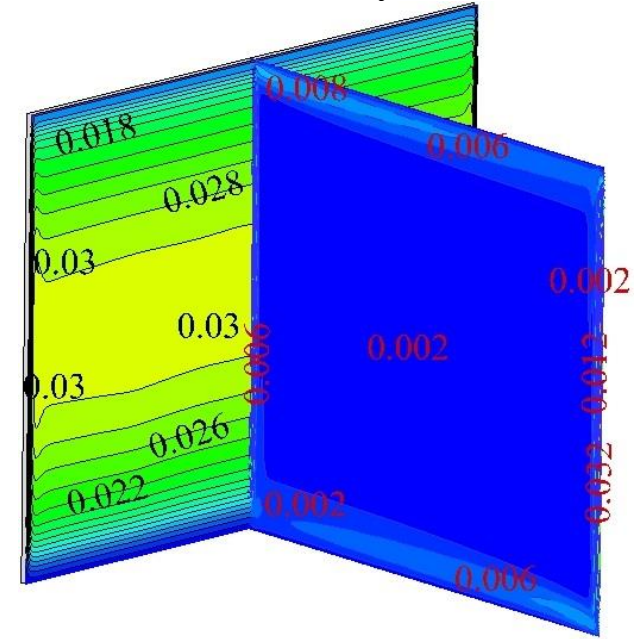

e) The EG-water-filled cavity,

$$
\mathrm{Ra}=7.97 \times 10^{8}
$$

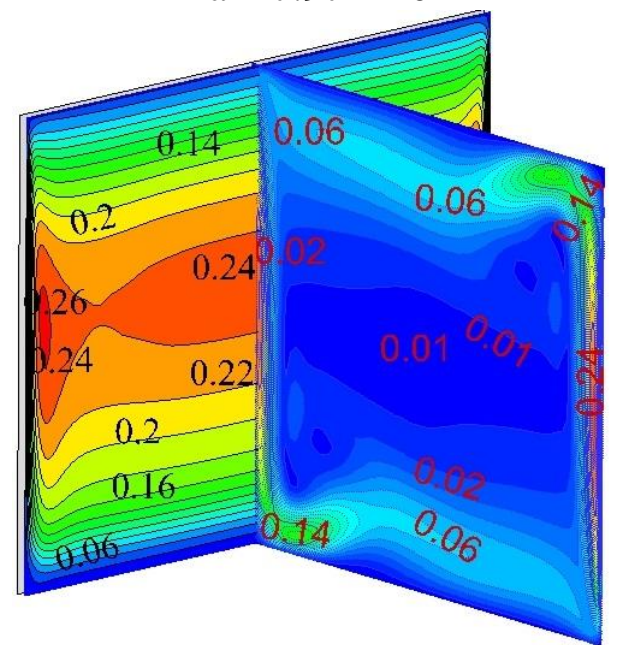

f) The air-filled cavity, $\mathrm{Ra}=4.52 \times 10^{6}$

Figure 7: Stream traces of fluid flow inside the cavity (only the cold wall is shown here) and non-dimensional velocity on the mid-vertical plane and a plane in the vicinity of the cold wall 
Figure 7 illustrates the patterns of stream traces for all fluids, as well as the distribution of non-dimensional velocity on the mid-vertical plane and close to the cold wall. The nondimensional velocity was defined as $\frac{V}{\sqrt{g \beta \Delta T L}}$. These images graphically explain the main differences between the natural convective flow regimes in a cavity. The highest velocity occurs in the air-filled cavity shown in Figure $7 \mathrm{f}$. The flow is rather distorted in this case, as opposed to the case of water and EG-water. Lower viscosity and density have also induced a large boundary layer and velocity for air in the cavity near the walls (diabatic and adiabatic). In the air-filled cavity, the velocity profile close to the cold wall proves that the insulated walls can influence the momentum that arises from the diabatic walls (the brownish area on the left of the non-dimensional velocity contour). On the other side, the stream traces and velocity for water and EG-water cavities are mostly flat inside the cavities and the momentum boundary layer is thin near all the walls. The non-dimensional velocity has a peak close to the diabatic walls and the rest is mainly flat for the water-filled cavity (Figure 7a), while a bigger circulation area expands from the hot wall to the middle of the cavity for the EG-water (Figure 7b). Since the viscosity of EG-water is higher than that of water (almost four times), the viscous friction force is bigger, which leads to a higher order of nondimensional velocity in the water-filled cavity. The flat distribution of velocity near the cold wall in both the water- and EG-water-filled cavities explain the lower impacts of the insulated walls on the main flow. As a result, the three-dimensional effects are greater in the air-filled cavity than in the case of the other two fluids. Nonetheless, these effects cannot be neglected in the case of water and EG-water.

The contour and three-dimensional profile of the local Nusselt number based on local heat flux are presented in Figure 8. The order of magnitude of the Nusselt number in the air cavity is almost 10 times less than in water- and EG-water-filled cavities. In all the cases, the local Nusselt number on the cold wall is slightly higher than that of the hot wall due to the favourable effect of gravity on the cold wall, while the fluid flows in the opposite direction of gravity as it passes over the hot wall. The slope of the graph is small below the bottom half of the hot wall and above the top half of the cold wall in the case of the water- and EG-waterfilled cavities. Then, it sharply decreases to the lowest value at the top and bottom of the hot and cold walls respectively. On the other hand, the trend is entirely different in the air-filled cavity. The Nusselt number changes almost linearly throughout the walls and is clearly affected by the side walls, as the graphs bend near the insulated walls. The lines of local Nusselt numbers are also straighter in the EG-water filled cavity than in the water-filled cavity, which means that it is less influenced in the $\mathrm{Z}$ direction.

The effects of thermal convective and diffusive terms at the mid-vertical plane from the hot to the cold walls are shown in Figure 9. With a simple manipulation of energy (Equation (4)) for a natural laminar convective flow, it can be rewritten as follows: 


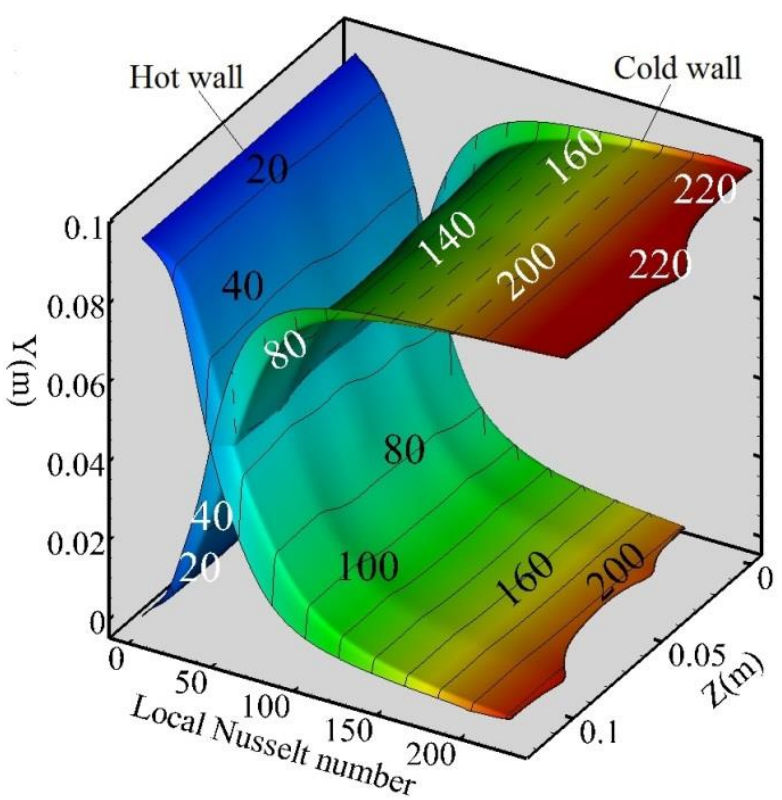

a) The water-filled cavity,

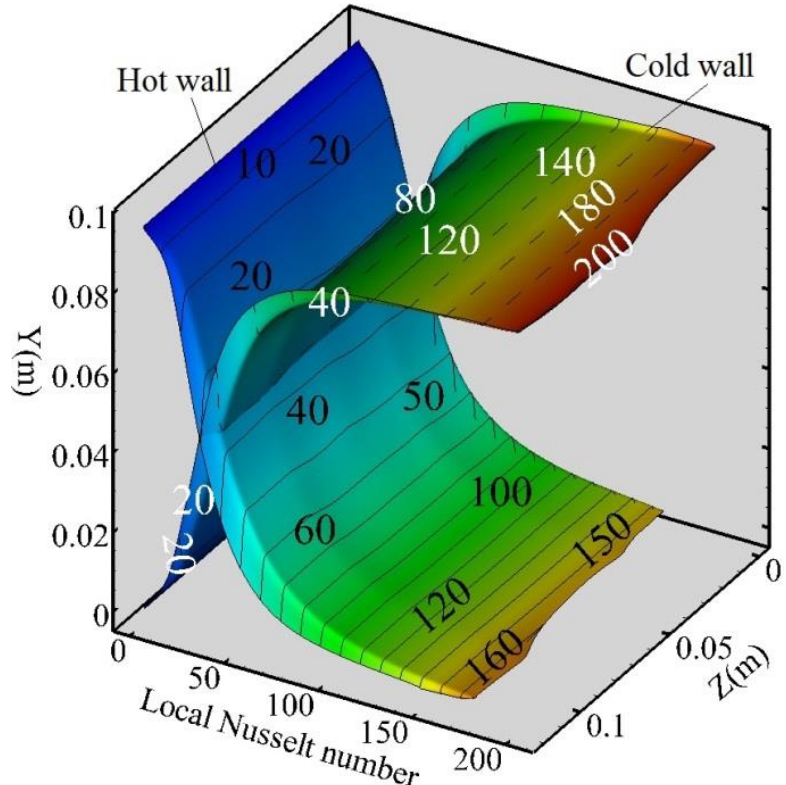

b) The EG-water-filled cavity, $\mathrm{Ra}=7.97 \times 10^{8}$ $\mathrm{Ra}=1.13 \times 10^{9}$

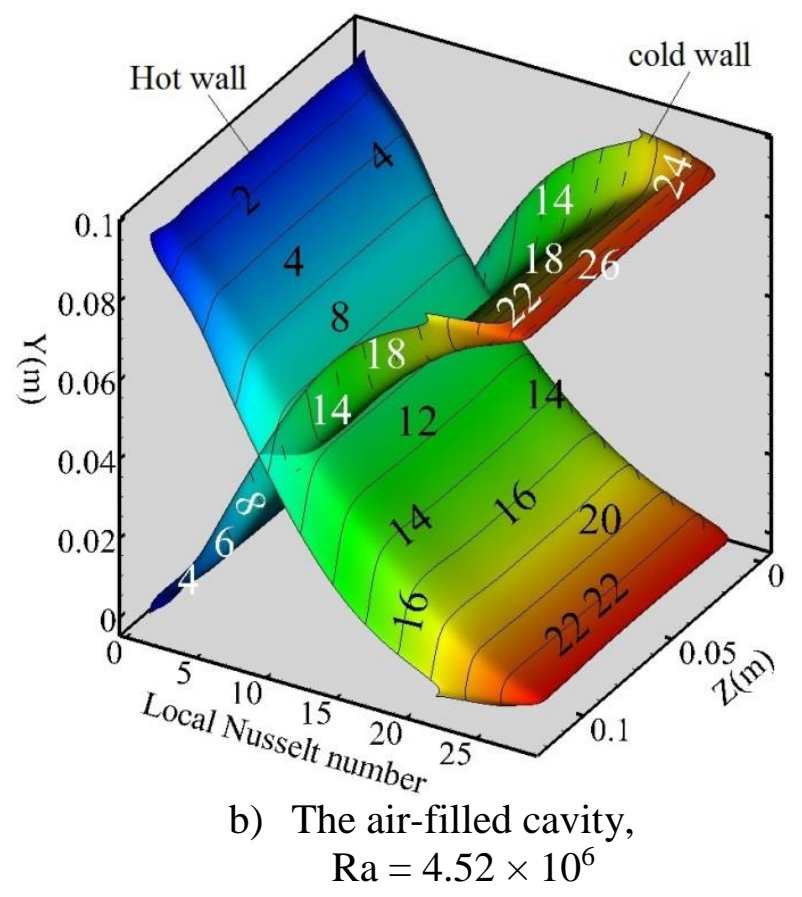

Figure 8: Distribution of the local Nusselt number on the hot and cold walls of the cavity

a) The water-filled cavity, $\mathrm{Ra}=2.27 \times 10^{8}$
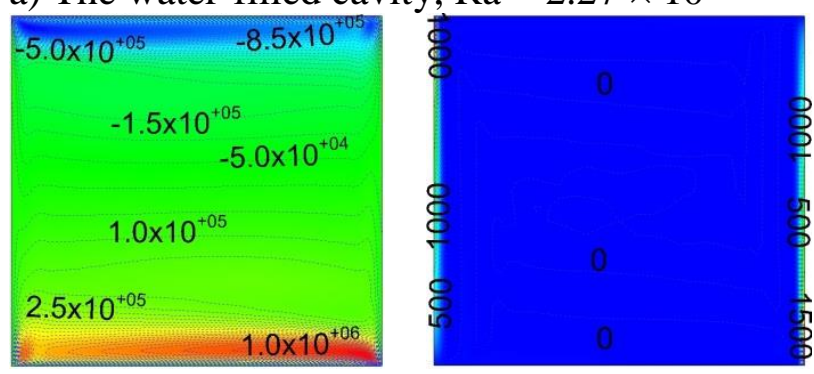

$\rho c_{p} u T k \frac{\partial T}{\partial x} \rho c_{p} v T k \frac{\partial T}{\partial y}$
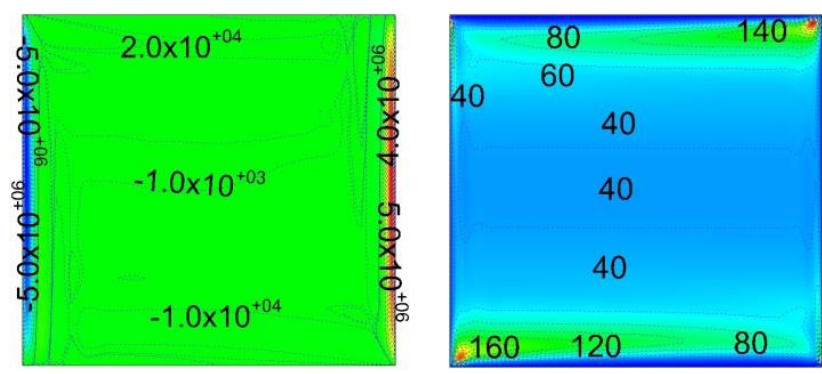
b) The EG-water-filled cavity, $\mathrm{Ra}=1.94 \times 10^{8}$
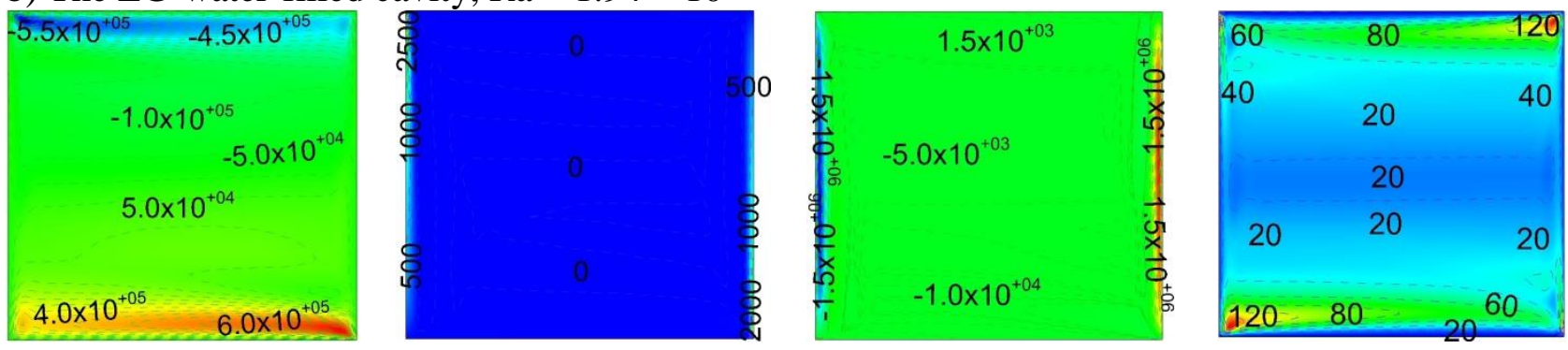

$\rho c_{p} u T k \frac{\partial T}{\partial x} \rho c_{p} v T k \frac{\partial T}{\partial y}$

c) The air-filled cavity, $\mathrm{Ra}=1.7 \times 10^{6}$
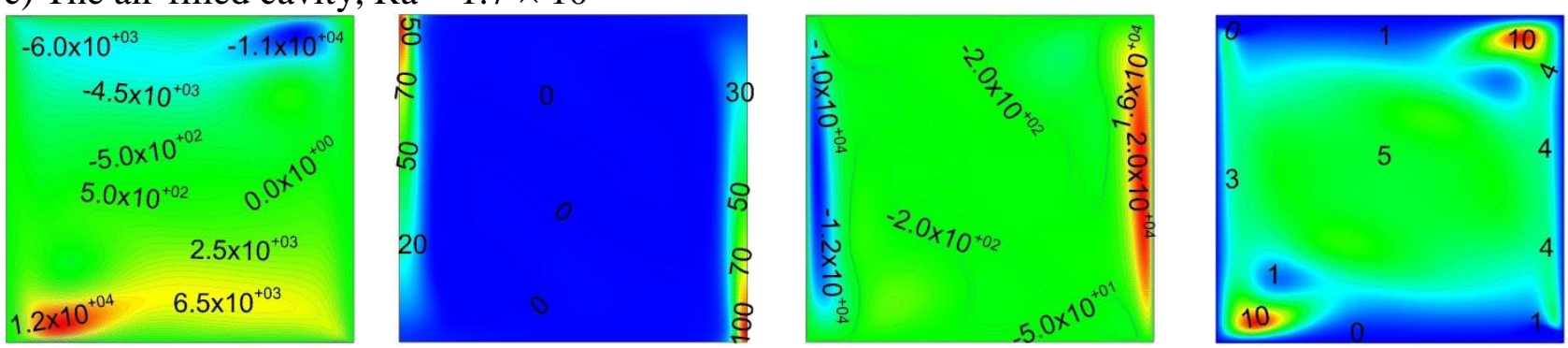

$\rho c_{p} u T k \frac{\partial T}{\partial x} \rho c_{p} v T k \frac{\partial T}{\partial y}$

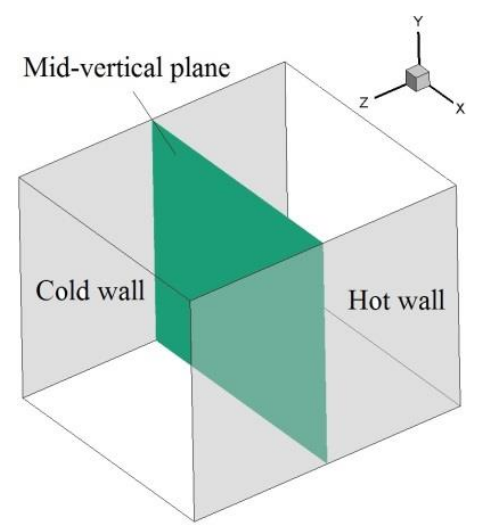

Figure 9: Distribution of heat flux due to convection and conduction in $\mathrm{X}$ and $\mathrm{Y}$ directions in the cavity flow at the mid-vertical plane from hot to cold walls (hot wall on the right and cold wall on the left; the bottom and top are insulated walls)

$\frac{\partial}{\partial x_{j}}\left(\rho c_{p} u_{j} T-k \frac{\partial T}{\partial x_{j}}\right)=0$

Evidently, the first term, $\rho c_{p} u_{j} T$, describes the impacts of fluid momentum on transferring energy or heat flux, and the second term, $k \frac{\partial T}{\partial x_{j}}$, comes from the thermal diffusion of conduction inside the flow. Ignoring the heat transfer in the $\mathrm{Z}$ direction, the equation can be expressed for the X-Y plane in Figure 9 as follows:

$$
\frac{\partial}{\partial x}\left(\rho c_{p} u T-k \frac{\partial T}{\partial x}\right)+\frac{\partial}{\partial y}\left(\rho c_{p} v T-k \frac{\partial T}{\partial y}\right)=0
$$


A comparison of the order of magnitude in convective and diffusive terms among the three fluids proves that the transport phenomenon in this cavity flow is dominated by convective and not conductive terms in both directions. The diffusive term of $k \frac{\partial T}{\partial x}$ is only dominant on the diabatic walls, since velocity $=0$. Even the $k \frac{\partial T}{\partial y}$ term can be neglected compared to the convective term $\rho c_{p} v T$ in the thermal boundary layer in the vicinity of the diabatic walls. The total process of energy transport in the cavity can be explained in two steps. In the first step, the energy is removed from the hot wall by the diffusive term, $k \frac{\partial T}{\partial x}$, and then the convective term, $\rho c_{p} v T$, induced by the buoyancy force in the momentum equation, carries the energy upstream. Eventually, it reaches the horizontal insulated wall, and from there the other convective term, $\rho c_{p} u T$, transports the energy to the cold wall.

For prediction purposes, the aspect ratio is considered to be four times the experimental setup, but the boundary conditions are similar to Test 5 of the EG-water in Table 4. The simulation results are presented in figures 10 to 12 . With the definition of aspect ratio as the vertical length of the diabatic wall in relation to the space between the two walls, $A R=3.76$ was achieved for this new case and $\mathrm{AR}=0.94$ was achieved for the cavity investigated in this study. The profile of non-dimensional temperature is more distorted on the insulated horizontal walls in $\mathrm{AR}=3.76$ than in $\mathrm{AR}=0.94$ due to the smaller gap between the walls and the extension of non-uniformity of temperature from the diabatic to the insulated walls in Figure 10a. Figure 10c and Figure 10d also indicate that the order of non-uniformity on the hot wall is higher in the case of $A R=3.76$ than in the case of $A R=0.94$. Furthermore, the size of the circulation area near the hot wall is noticeable in Figure 11a in comparison to Figure $7 \mathrm{~b}$ for $\mathrm{AR}=0.94$. The trend of the local Nusselt number on the hot and cold walls for $\mathrm{AR}=3.76$ in Figure 12 is almost similar to Figure $8 \mathrm{~b}$, while the order of magnitude is a fourth that because of the small characteristic length in the Nusselt correlation with $\mathrm{AR}=3.76$.

The commonly used correlation for the calculation of uncertainty in terms of percentage is defined as:

$$
\frac{\Delta F}{F}=\sum \frac{1}{F} \frac{\partial F}{\partial p_{i}} \Delta p_{i},
$$

where $F$ and $p$ are the target functions and measured parameters respectively. The accuracy of the thermocouples, length and mass flow rate measurement is $\pm 0.02{ }^{\circ} \mathrm{C}, 0.01 \mathrm{~cm}$ and $2 \%$ of read value by the data acquisition system respectively. Therefore, uncertainty analyses in terms of percentage reveal 3\% to 5.5\% for the Rayleigh number, and 5\% to $8.5 \%$ for the heat transfer and Nusselt number. The level of uncertainty for the heat transfer and Nusselt number only reaches $20 \%$ in the case of Test 5 for both water and EG-water because of the low amount of heat transfer.

\section{Conclusion}

Laminar natural convective flow inside a rectangular cavity with differentially heated walls and an aspect ratio of 0.94 for water and EG-water was investigated experimentally and 
numerically. The early tests were performed with an air-filled cavity as the benchmark. The simulation results of the air cavity were presented for further discussion. This study was inspired by the fact that no experimental reports were found for EG-water-filled cavities and a lack of sufficient experimental work for water-filled cavities. Experimental results showed that it is not easy to reach a uniform wall temperature with water- and EG-water-filled cavities, while this was achieved in all the tests with an air-filled cavity. Therefore, it was important to model all the setups, including two heat exchangers and the cavity between them, which is the main advantage of this study compared to other works. The numerical outcomes were found to be in good agreement with experimental measurements. The EGwater-filled cavity showed more uniformity of temperature in the walls and inside the heat exchangers than the water-filled cavity. The distribution of non-dimensional temperature in the walls indicated that the temperature gradient in the horizontal direction is small compared to the vertical direction. On the other hand, the influence of insulated walls on the sides cannot be neglected, especially in the case of the air-filled cavity, as shown by the stream traces and contours of the non-dimensional flow temperature near the cold wall. These effects were observed on the three-dimensional local Nusselt number for the hot and cold walls. The changes in local Nusselt numbers on the diabatic walls seem rather parabolic for the waterand EG-water-filled cavities, while the trend is almost linear for the air-filled cavity, except near the adiabatic side walls. The three-dimensional behaviour of air in the cavity is more noticeable than that of the two other fluids in this study. The roles of convective and diffusive terms were studied quantitatively, and it was revealed that only the temperature gradient in the $\mathrm{X}$ direction on the walls is an effective term in heat flux transfer, and that thermal diffusion does not have a role to play in the flow. The energy is removed from the diabatic walls by $\mathrm{Y}$ momentum and carried by $\mathrm{X}$ momentum to the insulated walls. 


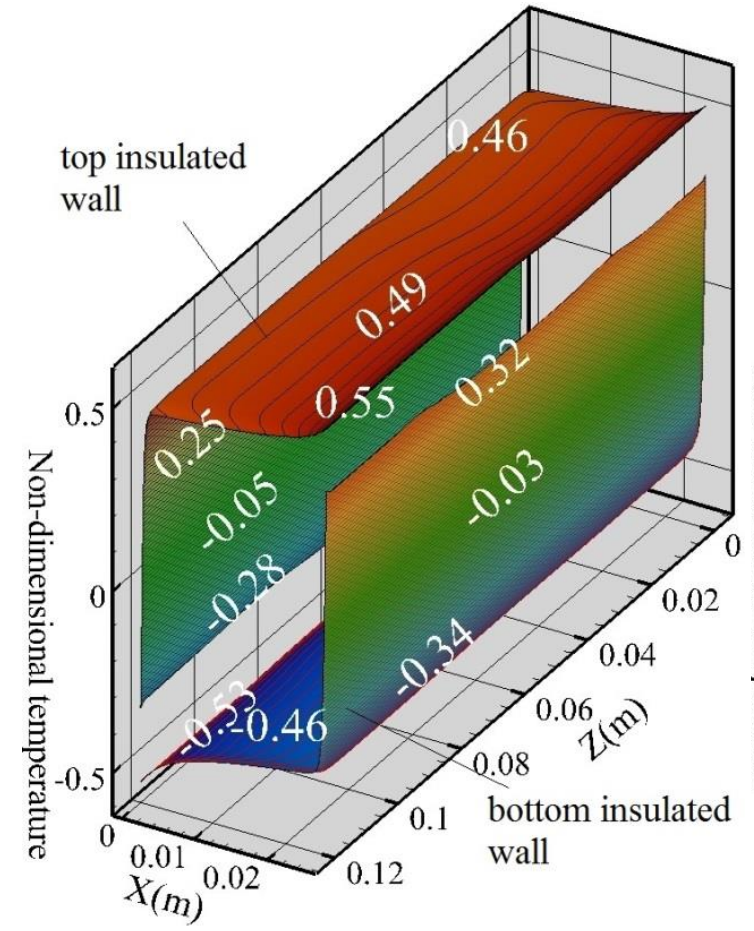

a) $\mathrm{Ra}=1.4 \times 10^{7}, \mathrm{AR}=3.76$

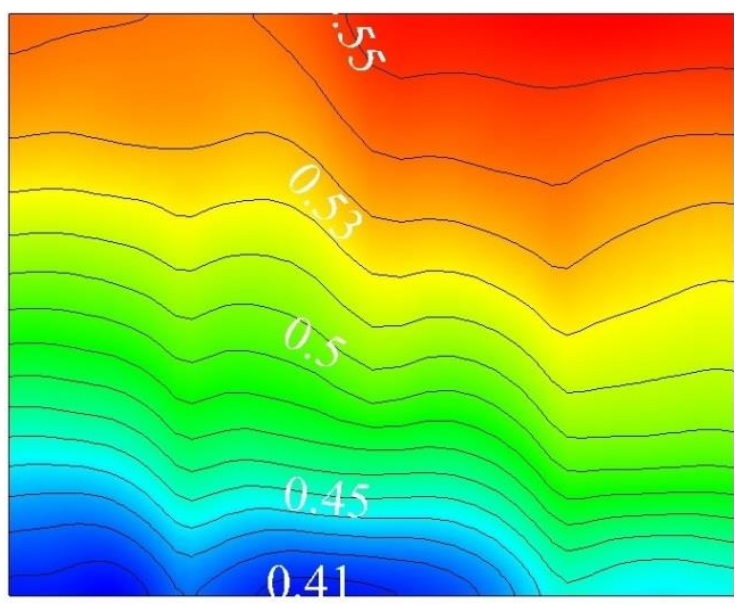

c) $\mathrm{Ra}=1.4 \times 10^{7}, \mathrm{AR}=3.76$

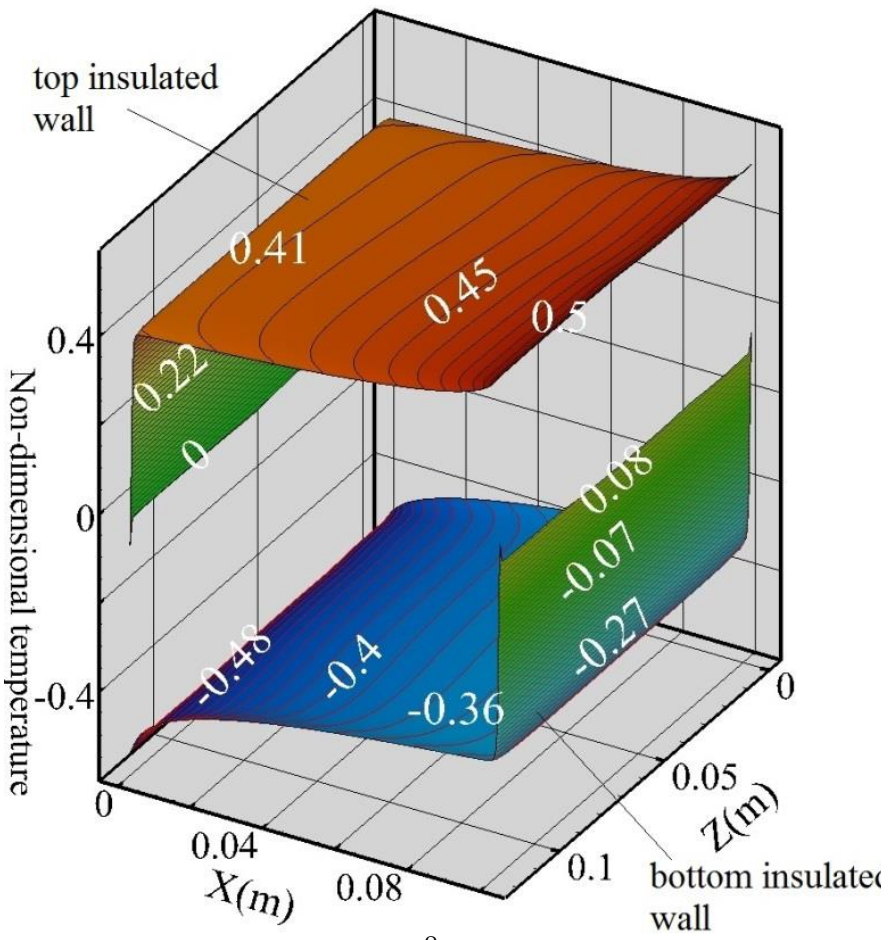

b) $\mathrm{Ra}=7.97 \times 10^{8}, \mathrm{AR}=0.94$

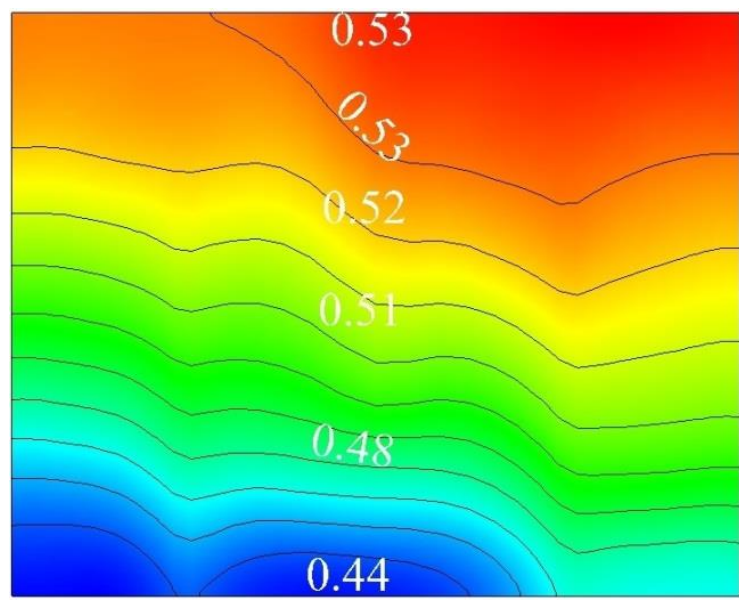

d) $\mathrm{Ra}=7.97 \times 10^{8}, \mathrm{AR}=0.94$

Figure 10: Distribution of non-dimensional temperature on the top and bottom horizontal adiabatic walls (a and b) and the hot wall of the EG-water-filled cavity (c and d) for different aspect ratios. 


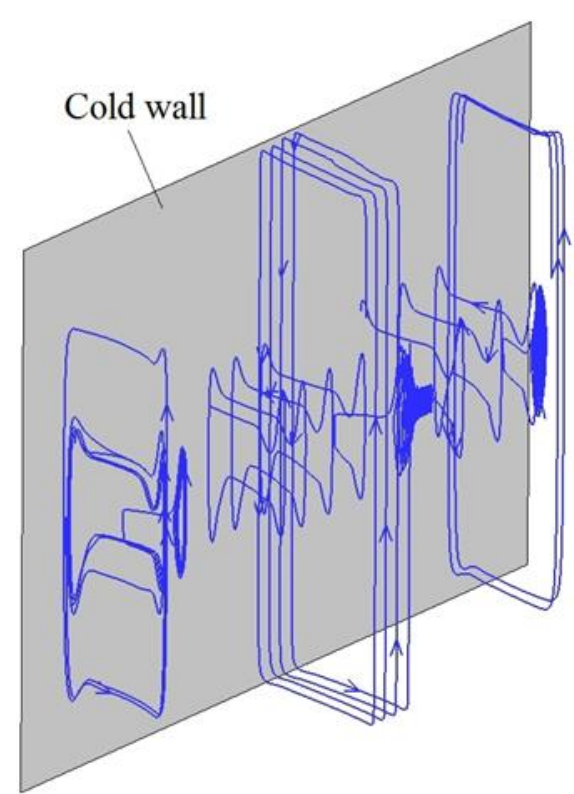

a)

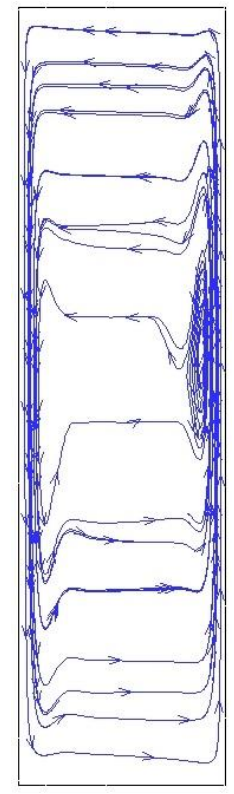

b)

Figure 11: a) Three-dimensional stream traces in an EG-water-filled cavity with $\mathrm{Ra}=1.4 \times 10^{7}$ and $\left.\mathrm{AR}=3.76 ; \mathrm{b}\right)$ two-dimensional stream lines in the mid-vertical plane

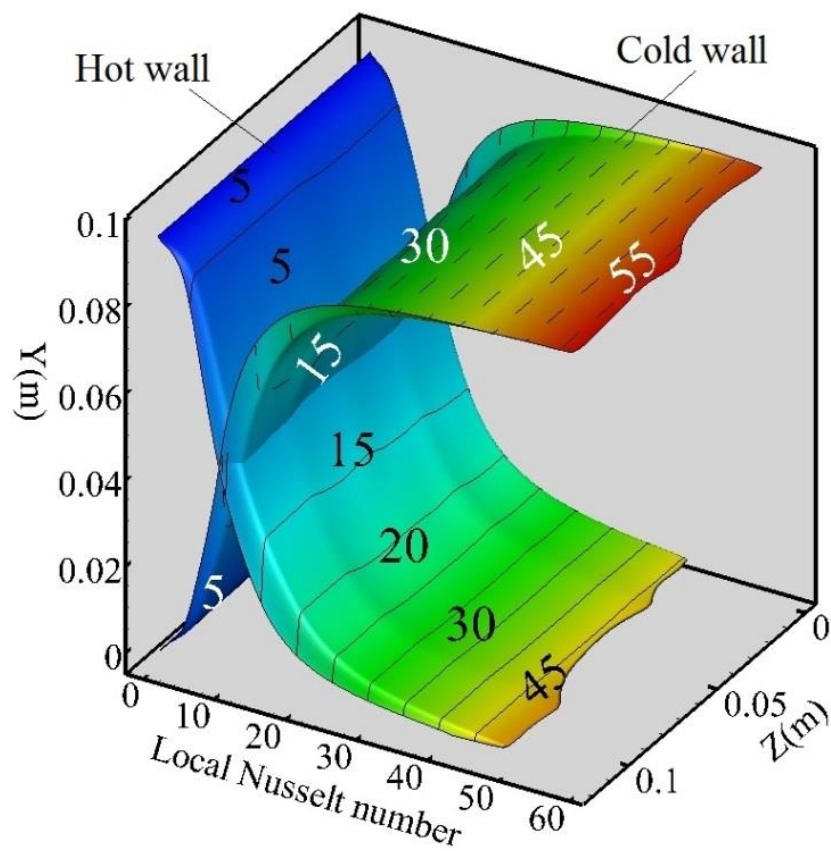

Figure 12: Local Nusselt number distribution on the hot and cold walls of the EG-water-filled cavity for $\mathrm{Ra}=1.4 \times 10^{7}$ and $\mathrm{AR}=3.76$ 


\begin{tabular}{|l|l|l|l|}
\hline \multicolumn{5}{|l|}{ Nomenclature } \\
\hline$c_{p}$ & Specific heat $(\mathrm{J} / \mathrm{kg} \cdot \mathrm{k})$ & Greek & \\
\hline$k$ & Thermal conductivity $(\mathrm{W} / \mathrm{m} . \mathrm{k})$ & $\alpha$ & Thermal diffusivity $\left(\mathrm{m}^{2} / \mathrm{s}\right)$ \\
\hline$k_{t}$ & Kinetic energy $\left(\mathrm{m}^{2} / \mathrm{s}^{2}\right)$ & $\beta$ & Thermal expansion coefficient $(\mathrm{l} / \mathrm{k})$ \\
\hline$L$ & Characteristic length $(\mathrm{m})$ & $\varepsilon$ & Turbulent dissipation rate $\left(\mathrm{m}^{2} / \mathrm{s}^{3}\right)$ \\
\hline$\dot{m}$ & Mass flow $(\mathrm{kg} / \mathrm{s})$ & $\mu$ & Dynamic viscosity $(\mathrm{kg} / \mathrm{m} . \mathrm{s})$ \\
\hline$N u$ & Nusselt number & $\mu_{t}$ & Turbulent viscosity $(\mathrm{kg} / \mathrm{m} . \mathrm{s})$ \\
\hline$u^{\prime}$ & Fluctuating velocity $(\mathrm{m} / \mathrm{s})$ & $\nu$ & Kinematic viscosity $\left(\mathrm{m}^{2} / \mathrm{s}\right)$ \\
\hline$u, V$ & Velocity $(\mathrm{m} / \mathrm{s})$ & $\rho$ & Density $\left(\mathrm{kg} / \mathrm{m}^{3}\right)$ \\
\hline$P$ & Pressure $(P a)$ & & \\
\hline$q^{\prime \prime}$ & Heat flux $\left(\mathrm{W} / \mathrm{m}^{2}\right)$ & Subscript & \\
\hline$R a$ & Rayleigh number & $c$ & Cold wall \\
\hline$T$ & Temperature & exp & Experimental \\
\hline & & $h$ & Hot wall \\
\hline & Abbreviations & in & Pipe inlet \\
\hline AR & Aspect ration & num & Numerical \\
\hline CFD & Computational fluid dynamics & out & Pipe outlet \\
\hline EG & Ethylene glycol & & \\
\hline
\end{tabular}

\section{References}

[1] G.D.V. Davis, Natural convection of air in a square cavity a benchmark numerical solution, International Journal for Numerical Methods in Fluids 3 (1983) 249-264.

[2] G.D.V. Davis, Natural convection in a square cavity: a comparison exercise, International Journal for Numerical Methods in Fluids 3 (1983) 227-248.

[3] W. Schmidt, P.W. Giel, R.E. Phillipst, D.F. Wang, A comparison of experimental and predicted results for laminar natural convection in an enclosure, International Journal of Heat and Fluid Flow 7 (1986) 183-190.

[4] T.J. Heindel, F.P. Incropera, S. Ramadhyani, Laminar natural convection in a discretely heated cavity: II - comparisons of experimental and theoretical results, Journal of Heat Transfer 117 (1995) 910-917.

[5] E. Shewen, K.G.T. Hollands, G. D. Raithby, Heat transfer by natural convection across a vertical air cavity of large aspect ratio, Journal of Heat Transfer 118 (1996) 993-995.

[6] T. Fusegi, J.M. Hyun, Laminar and transitional natural convection in an enclosure with complex and realistic conditions, International Journal of Heat and Fluid Flow 15 (1994) $258-268$.

[7] O. Hiroyuki, M. Akira, O. Masaru, Numerical calculations of laminar and turbulent natural convection in water in rectangular channels heated and cooled isothermally on the opposing vertical walls, International Journal of Heat and Mass Transfer 28 (1985) 125-138. 
[8] B. Lartigue, S. Lorente, B. Bourret, Multicellular natural convection in a high aspect ratio cavity: experimental and numerical results, International Journal of Heat and Mass Transfer 43 (2000) 3157-3170.

[9] F. Ampofo, T.G. Karayiannis, Experimental benchmark data for turbulent natural convection in an air-filled square cavity, International Journal of Heat and Mass Transfer 46 (2003) 3551-3572.

[10] A. Bairi, N. Laraqi, J.M. Garcia de Maria, Numerical and experimental study of natural convection in tilted parallelepipedic cavities for large Rayleigh numbers, Experimental Thermal and Fluid Science 31 (2007) 309-324.

[11] K.S. Hwang, J.H. Lee, S.P. Jang, Buoyancy-driven heat transfer of water-based $\mathrm{Al}_{2} \mathrm{O}_{3}$ nanofluids in a rectangular cavity, International Journal of Heat and Mass Transfer 50 (2007) 4003-4010.

[12] B. Ghasemi, S.M. Aminossadati, Natural convection heat transfer in an inclined enclosure filled with a water-CuO nanofluid, Numerical Heat Transfer, Part A: Applications, International Journal of Computation and Methodology 55 (2009) 807-823.

[13] C.J. Ho, D.S. Chen, W.-M. Yan, O. Mahian, Buoyancy-driven flow of nanofluids in a cavity considering the Ludwig-Soret effect and sedimentation: numerical study and experimental validation, International Journal of Heat and Mass Transfer 77 (2014) 684694.

[14] I. Rashidi, O. Mahian, G. Lorenzini, C. Biserni, S. Wongwises, Natural convection of $\mathrm{Al}_{2} \mathrm{O}_{3}$ /water nanofluid in a square cavity: effects of heterogeneous heating, International Journal of Heat and Mass Transfer 74 (2014) 391-402.

[15] G. Yesiloz, O. Aydin, Natural convection in an inclined quadrantal cavity heated and cooled on adjacent walls, Experimental Thermal and Fluid Science 35 (2011) 1169-1176.

[16] O. Aydin, G. Yesiloz, Natural convection in a quadrantal cavity heated and cooled on adjacent walls, Journal of Heat Transfer 133 (2011) 052501-1.

[17] F. Xu, J.C. Patterson, C. Lei, An experimental study of the coupled thermal boundary layers adjacent to a partition in a differentially heated cavity, Experimental Thermal and Fluid Science 54 (2014) 12-21.

[18] J. Imberger, Natural convection in a shallow cavity with differentially heated end walls. Part 3. Experimental results, Journal of Fluid Mechanics 65 (1974) 247-260.

[19] O. Turan, R.J. Poole, N. Chakraborty, Influences of boundary conditions on laminar natural convection in rectangular enclosures with differentially heated sidewalls, International Journal of Heat and Fluid Flow 33 (2012) 131-146.

[20] W. Wu, C.Y. Ching, The effect of the top wall temperature on the laminar natural convection in rectangular cavities with different aspect ratios, Journal of Heat Transfer 131 (2009) 052501-1. 
[21] P. Kumar, V. Eswaran, A numerical simulation of combined radiation and natural convection in a differential heated cubic cavity, Journal of Heat Transfer 132 (2010) 023501-1.

[22] F. Corvaro, M. Paroncini, An experimental study of natural convection in a differentially heated cavity through a 2D-PIV system, International Journal of Heat and Mass Transfer 52 (2009) 355-365.

[23] D. Kizildag, I. Rodríguez, A. Oliva, O. Lehmkuhl, Limits of the Oberbeck-Boussinesq approximation in a tall differentially heated cavity filled with water, International Journal of Heat and Mass Transfer 68 (2014) 489-499.

[24] M. Corcione, Heat transfer features of buoyancy-driven nanofluids inside rectangular enclosures differentially heated at the sidewalls, International Journal of Thermal Sciences 49 (2010) 1536-1546.

[25] E. Abu-Nada, A. Chamkha, Effect of nanofluid variable properties on natural convection in enclosures filled with a CuO-EG-water nanofluid, International Journal of Thermal Sciences 49 (2010) 2339-2352.

[26] K. Hermanson, S. Kern, G. Picker, S. Parneix, Predictions of external heat transfer for turbine vanes and blades with secondary flowfields, Journal of Turbomachinery 125 (2003) 107-113.

[27] Q.W. Wang, M. Lin, M. Zeng, Effect of lateral fin profiles on turbulent flow and heat transfer performance of internally finned tubes, Applied Thermal Engineering 29 (2009) 3006-3013.

[28] ANSYS Inc, ANSYS-FLUENT 15.0 User manual (2014), ANSYS: Canonsburg, PA.

[29] D.G. Kröger, Air-cooled heat exchangers and cooling towers, Thermal-flow performance evaluation and design 2 (2004).

[30] American Society of Heating, Refrigerating and Air-conditioning Engineers, ASHRAE Handbook: Fundamentals (2009), 31.1-13. 